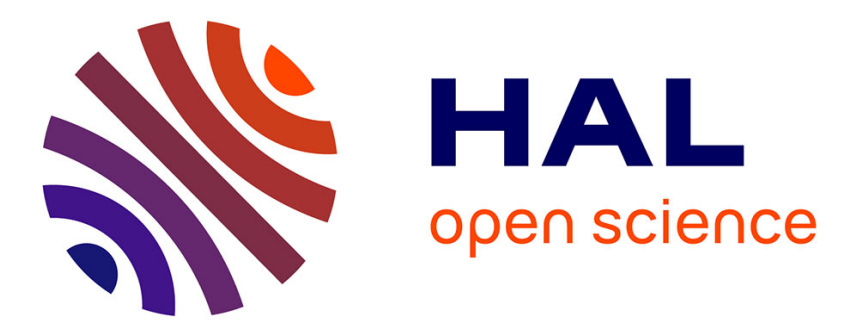

\title{
Surface functionalization of nanomaterials by aryl diazonium salts for biomedical sciences
}

Da Li, Yun Luo, Delphine Onidas, Li He, Ming Jin, Florence Gazeau, Jean Pinson, Claire Mangeney

\section{- To cite this version:}

Da Li, Yun Luo, Delphine Onidas, Li He, Ming Jin, et al.. Surface functionalization of nanomaterials by aryl diazonium salts for biomedical sciences. Advances in Colloid and Interface Science, 2021, 294, pp.102479. 10.1016/j.cis.2021.102479 . hal-03391594

\author{
HAL Id: hal-03391594 \\ https://hal.science/hal-03391594
}

Submitted on 21 Oct 2021

HAL is a multi-disciplinary open access archive for the deposit and dissemination of scientific research documents, whether they are published or not. The documents may come from teaching and research institutions in France or abroad, or from public or private research centers.
L'archive ouverte pluridisciplinaire HAL, est destinée au dépôt et à la diffusion de documents scientifiques de niveau recherche, publiés ou non, émanant des établissements d'enseignement et de recherche français ou étrangers, des laboratoires publics ou privés.

\section{(1)(1) $\$(0)$}

Distributed under a Creative Commons Attribution - NonCommercial - ShareAlikel 4.0 


\title{
Surface Functionalization of Nanomaterials by Aryl Diazonium Salts for Biomedical Sciences
}

$\mathrm{Da} \mathrm{Li}^{\mathrm{a}}$, Yun Luo ${ }^{\mathrm{a}}$, Delphine Onidas ${ }^{\mathrm{a}}, \mathrm{Li} \mathrm{He}^{\mathrm{a}}$, Ming Jin ${ }^{\mathrm{a}}$, Florence Gazeau ${ }^{\mathrm{b}}$, Jean Pinson ${ }^{\mathrm{c}}$ and Claire Mangeney ${ }^{\mathrm{a} *}$
a. Université de Paris, LCBPT, CNRS, F-75006 Paris, France.
b. Université de Paris, MSC, CNRS, F-75013 Paris, France.
c. Université de Paris, ITODYS, CNRS, F-75013 Paris, France.

\begin{abstract}
Nanoparticles (NPs) can be prepared by simple reactions and methods from a number of materials. Their small size opens up a number of applications in different fields, among which biomedicine, including: i) drug delivery, ii) biosensors, iii) bioimaging, iv) antibacterial activity. To be able to perform such tasks, NPs must be modified with a variety of functional molecules, such as drugs, targeting groups, chemical tags or antibacterial agents, and must also be prevented from aggregation. The attachment must be stable to resist during the transportation to the targeted location. Diazonium salts, which have been widely used for coupling applications and surface modification, fulfil such criteria. Moreover, they are simple to prepare and can be easily substituted with a large number of organic groups. This review describes the use of these compounds in nanomedicine with a focus on the construction of nanohybrids derived from metal, oxide and carbon-based NPs as well as viruses.
\end{abstract}

Keywords: Nanoparticles, Surface functionalization, Aryldiazonium salts, Biomedical applications

\section{Contents}

1. Introduction .2

2. The grafting of nanoparticles by aryldiazonium salts. .5

2.1 Generalities on the surface chemistry of diazonium salts .5

2.2 Surface modification of nanoparticles by diazonium salts.....................5

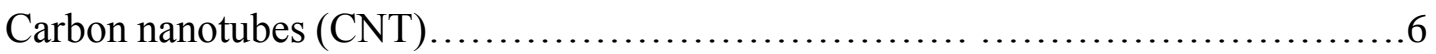

Graphene nanoplatelets.............................................6 6

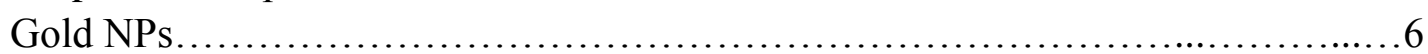

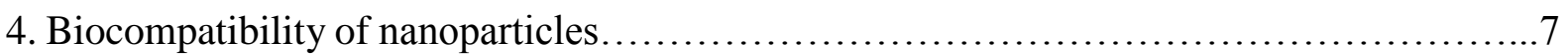

5. Functionalization of NPs by aryldiazonium salts for drug delivery applications............8

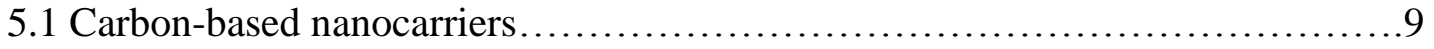

Graphene derivatives..............................................9

Nanoscale diamonds. ................................................. 12

5.2 Metallic and oxide nanoparticles........................................ 12

Gold nanoparticles.................................................. 12

Iron oxide nanoparticles.............................................12

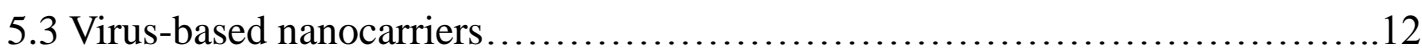


6. Functionalization of NPs by aryldiazonium salts for nano-biosensors. .15

$6.1 \mathrm{MIP}$ biosensors ..................................................... 15

6.2 Biosensors based on biological recognition................................ 16

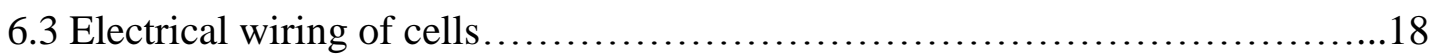

7. Nanotracers modified by aryldiazonium salts for bioimaging.........................18

8. Antibacterial properties of NPs functionalized by aryldiazonium salts.................22

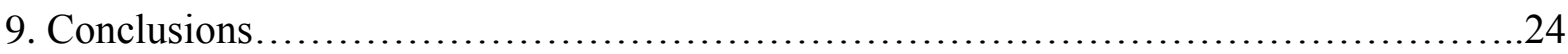

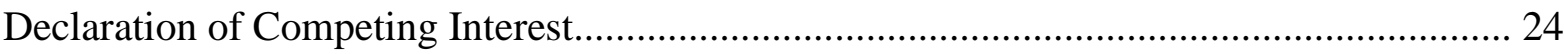

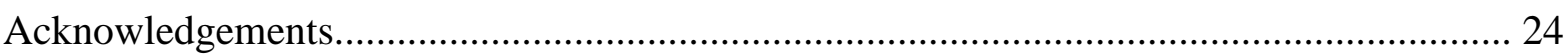

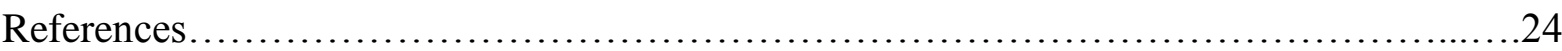

\section{INTRODUCTION}

Nanoparticles are characterized by their small dimensions $(<100 \mathrm{~nm})$ and can be obtained from many different materials: carbon in its various allotropic forms, metals [1-2] and their oxides,[3] semiconductors, [4] polymers, [5] dendrimers, [6] proteins, [7] and lipids.[8] Although they have been known for a long time, the recent interest in these objects is related to the possible modification (or functionalization) and analysis of their surface and structure with modern methods. Indeed, for such nano-objects the surface to volume ratio is very high and many of their properties are dictated by their surface chemistry. As their dimensions are similar to those of many subcellular organelles (ribosomes, proteasomes, ion channels, and transport vesicles), their possible introduction inside cells and their use for biomedical applications have stimulated a wide interest. [9] Among the possible uses of nanoparticles in this field, drug delivery,[10] biosensors,[11] imaging [12] and antibacterial activities [13] were most often targeted. Drug delivery by NPs involves the modification of NPs by molecules (drugs, for example) that can be released in highly specific locations. This is a complex process: the NP functionalized with a drug must be transported without alteration to the targeted site where it should release the drug under the action of enzymes or upon a modification of the environment ( $\mathrm{pH}$ change, for example). This involves a critical step: the passage through the cell membranes.[14] Thanks to recognition properties, nanoparticle-based drug delivery systems [15] are expected to increase safety and efficiency of drug release and reduce side effects. In contrast, conventional drug delivery faces limited drug absorption, short half-life, poor specificity, low therapeutic index and thus requires large volume of distribution. This can be the cause of unwanted side effects, like skin reactions, hypersensitivity and peripheral neuropathy induced by drug distribution in healthy tissues.[16-17] Thus, targeting delivery by surface-modified NPs is an attractive strategy to release locally the therapeutic/diagnostic agents and to reduce systemic exposure of drugs. The construction of a NP biosensor involves the stable attachment of a group able to specifically recognize the analyte. In addition, a second group is often added to act as a reporter indicating the successful recognition, leading to very complex systems. For bioimaging, NPs that emit or absorb a signal should be modified to specifically recognize a target and accumulate at the site to be observed. Modified or not, NPs can present antibiotic activities. In this case, they may not target a specific location but be spread on a surface to prevent the adhesion or to destroy microorganisms, bacteria. 
The main advantages of NPs in biomedical applications are their distinct characteristics, such as adjustable materials [18-20], and size, diverse shapes, easy synthesis process, tunable surface properties and biocompatibility. To achieve efficient biomedical activity, the surface of the nanoparticles must be modified to attach the drug, and/or the reporter group and/or a targeting group. Surface functionalization is also crucial in order to prevent the aggregation of NPs in biological environment, which makes them lose their nano-character. Different methods permit the modification of NP surface,[21] generally classified into two categories: adsorption (also referred as physisorption) [22] and covalent bonding (also referred as chemisorption). The last one provides more stable bonding and prevents the release of the coating during the transport of the NP before it reaches its final target. Therefore, the covalent bonding is preferred for biomedical applications of NPs. Several methods have been developed for the covalent modification of surfaces [23]: reaction of silanes [24] or carboxylic [25] and phosphonic acids [26] on surface oxides, reaction of long alkyl chain thiols on gold and silver,[27] reaction of carbenes [28] on metals. Each of these methods is restricted to a specific type of surface. On the contrary, aryldiazonium salts [29-31] react with many different surfaces to provide a strong interfacial bonding of aryl groups, [32] which explains the success of this reaction. This reaction involves the formation of an aryl radical [33] upon dediazonation. This dediazonation can be spontaneous, for example by reaction with the solvent, or triggered by the transfer of an electron from a reducing agent [34] or an electrode [35-36] but it can also be driven by photochemistry.[37-39] The surface modification of NPs for biomedical applications can be achieved with diazonium salts in two ways,[40] as depicted in Figure 1.

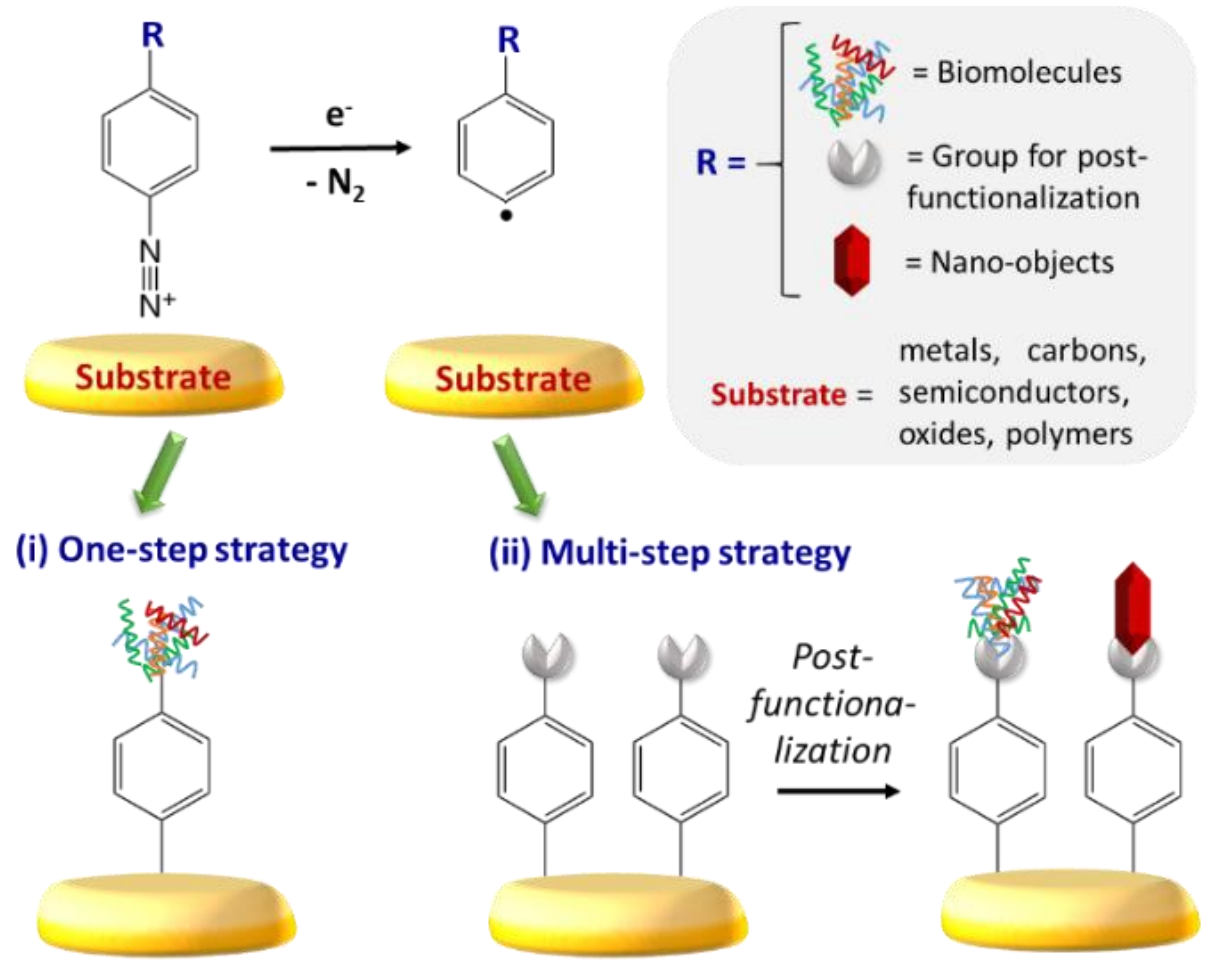

Figure 1. Schematic presentation of the grafting of NPs by diazonium salts. For sake of simplicity, the transfer of an electron is shown, but many other methods are available that permit this reaction (see below). 
The first strategy involves the direct grafting of NPs by the molecule of interest (drug, protein, antibody...) that has been equipped with a diazonium group. The second strategy (post-functionalization) is based on the modification of the NPs by a diazonium salt bearing a simple reactive substituent (most often $-\mathrm{COOH},-\mathrm{CH}_{2} \mathrm{COOH},-\mathrm{NH}_{2},-\mathrm{CH}_{2} \mathrm{NH}_{2}$ in the 4-position of the aryl ring). This reactive platform is then attached to more complex molecules through high yield, fast reactions taking place at low temperature (for example, 1-ethyl-3-(3-dimethylaminopropyl)carbodiimide (EDC) coupling to obtain esters and amines, click chemistry between acetylenic groups and azides, ...).

In addition to the above radical surface modification, another reaction can take place between diazonium salts and the tyrosine residues of proteins or viruses. The mechanism of this aromatic electrophilic substitution reaction is depicted in Figure 2. It leads to an azo compound. [41]

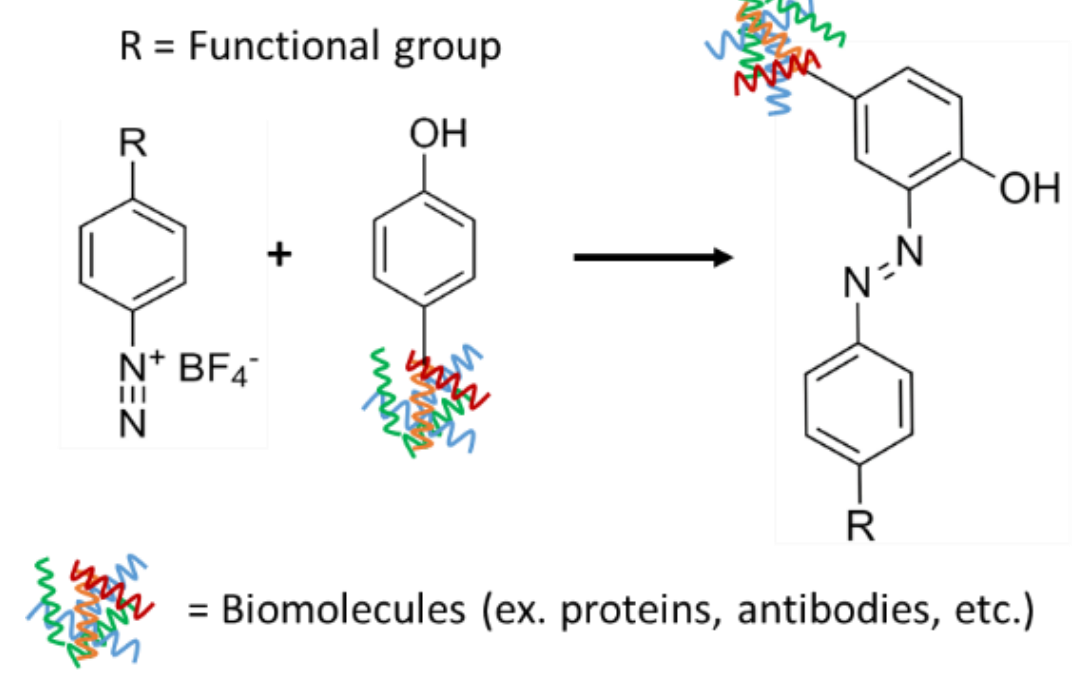

Figure 2. Schematic representation of the electrophilic aromatic substitution of diazonium salts.

This review covers a brief overview of i) the surface chemistry of diazonium salts; ii) the surface modification of NPs and the different biomedical applications (Figure 3), which will be divided into four main sections, focusing on: iii) drug delivery systems; iv) biosensors; v) bioimaging and vi) antibacterial materials. Perspectives of aryl diazonium salt surface chemistry for future researches in nanomedicine are also provided. 


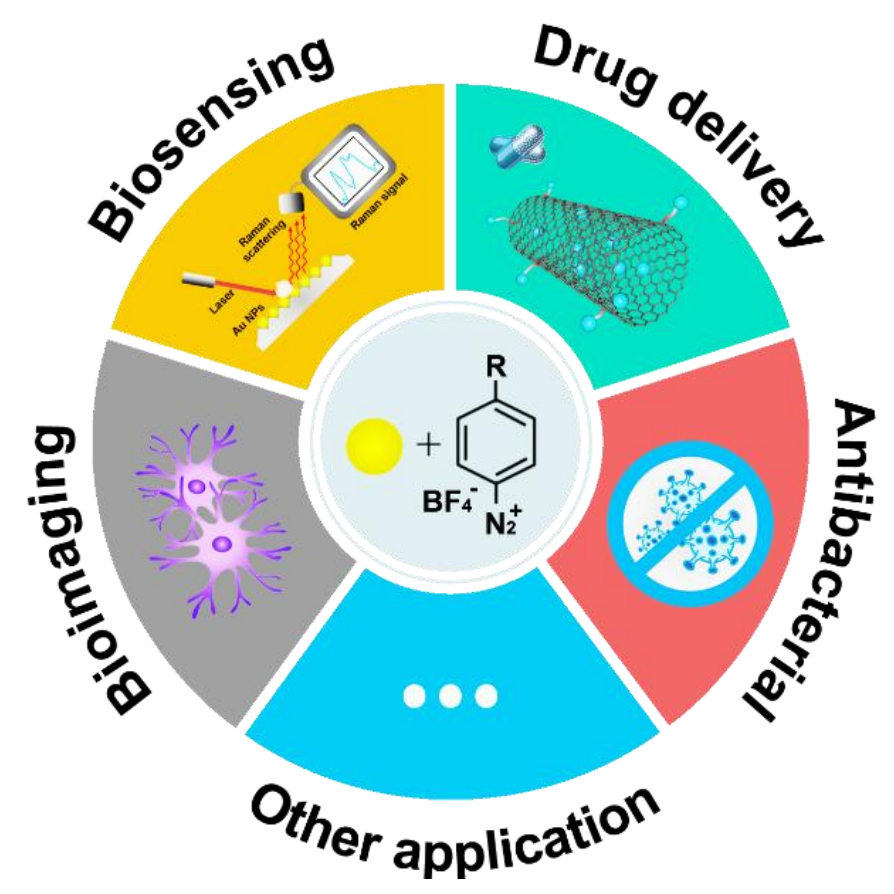

Figure 3. Representative scheme of aryl diazonium salt surface chemistry for NPs functionalization and related biomedical applications.

\section{THE GRAFTING OF NANOPARTICLES BY DIAZONIUM SALTS}

\subsection{Generalities on the surface chemistry of diazonium salts}

As the modification of surfaces by reaction with diazonium salts has been thoroughly reviewed, [29-31, 42-43] we will only briefly recall the main features. Diazonium salts are easily prepared in one step from the corresponding anilines, many of which are commercially available. The simplest way involves the addition of $\mathrm{NaNO}_{2}$ to a solution of the aromatic amine in $\mathrm{HBF}_{4}$ and the direct use of this solution without isolation of the salt. Several grafting methods can be used to functionalize surfaces using diazonium salts, including spontaneous reactions, electrochemistry, addition of reducing agents or photochemistry. Most of them involve fast (less than an hour) and user-friendly protocols under mild conditions (water solvent or acetonitrile, room temperature, in the presence of air). Diazonium salts are involved in a number of reactions such as Sandmeyer,[44] Meerwein [45] or Gomberg-Bachman [46]. The surface chemistry of aryldiazonium salts, $\mathrm{Ar}-\mathrm{N} \equiv \mathrm{N}_{2}{ }^{+} \mathrm{X}^{-}\left(\mathrm{Ar}=\right.$ substituted aryl group and $\mathrm{X}^{-}$ = inorganic or organic anion) is dominated by the loss of dinitrogen. The cleavage can occur in a homolytic or heterolytic manner giving respectively $\mathrm{Ar}^{*}$ or $\mathrm{Ar}^{+}$. The aryl radical, obtained by reduction and/or homolytic cleavage, is the key specie in the reaction of diazonium salts with surfaces.[47] The stability of diazonium salts depends on the substituents, and on their counter ions. Explosions have been reported during their use;[48], [49] therefore, only tetrafluoroborates $\left(\mathrm{BF}_{4}^{-}\right)$and triflates $\left(\mathrm{CF}_{3} \mathrm{SO}_{3}{ }^{-}\right)$should be used as counter ions as they provide stable diazonium ions.[50] In aprotic solvents, diazonium salts are stable in acetonitrile (ACN) which is most often used for surface grafting. In aqueous solution, the diazonium salts present two $\mathrm{pK}_{\mathrm{a}}$ corresponding to the formation of diazohydroxide $(\mathrm{Ar}-\mathrm{N}=\mathrm{N}-\mathrm{OH})$ and diazoates $(\mathrm{Ar}-\mathrm{N}=\mathrm{N}-\mathrm{O}-)$ as the $\mathrm{pH}$ increases. As a consequence, diazonium salts are stable in aqueous 
acidic medium, but diazohydroxides and diazoates undergo spontaneous homolytic dediazonation to give $\mathrm{Ar}^{\bullet}$ that further reacts on surfaces.[51-52] The same radical is obtained by spontaneous cleavage of diazoethers $\mathrm{Ar}-\mathrm{N}=\mathrm{N}-\mathrm{OR},[53]$ obtained by reaction of diazonium salts with alcohols. In the presence of amines, triazenes are obtained that, at the contrary of diazonium salts, are stable in basic medium but cleave to $\mathrm{Ar}^{*}$ in acidic medium.[54] On macroscopic surfaces, electrografting of diazonium salts is mostly used, where the surface to be grafted is the cathode; it transfers one electron to a diazonium cation to give the aryl radical that reacts with the surface.[55] However, this method is not convenient with nanoparticles and the radical has to be produced either by spontaneous dediazonation as described above or by addition of a mild reducing agent (iodine, [34] hypophosphorous acid,[56-57]....). Note that in some cases, the NP itself can reduce the diazonium salt (iron NPs, for example [58]). Due to the radical character of the reaction, multilayers are obtained and it is possible to build layer-on-layer assemblies by reaction of different diazonium salts.[59]

\subsection{Surface modification of nanoparticles by diazonium salts}

A few reviews have reported the surface modification of nanoparticles by diazonium salts. [31, 60-61] The different methods that permit the functionalization of macroscopic surfaces by diazonium salts also apply to NPs (reduction, dediazonation in neutral and basic medium, photochemistry) but electrochemistry is unpractical. The grafting mechanism, [29, 62] the structure of the films (formation of multilayers by attack of the aryl radicals on the first grafted groups) and the covalent link based on carbon-, semiconductor-, metal-aryl or oxide-aryl bonds are similar to what is observed on macroscopic samples. The characterization of the modified NPs is possible by the classical methods, such as infrared (IR) and Raman spectroscopy, X-ray photoelectron spectroscopy (XPS), but some methods are possible with NPs and not with macroscopic surfaces. For example, nuclear magnetic resonance (NMR) [63-64] spectroscopy, thermogravimetric analysis (TGA), coupled with mass spectroscopy (TGA-MS), [65-66] and transmission electron microscopy (TEM) permit a fine characterization of the film.[67] The topic "nanoparticles and diazonium salts" involves the reaction of nanoparticles with diazonium salts but also the attachment of nanoparticles to surfaces modified by diazonium

salts. This review covers both cases. In this section, we review the different nanoparticles which have been successfully modified by diazonium salts.

Carbon nanotubes (CNT). Their reaction with diazonium salts has been included in several reviews [61, 68] and a number of papers have dealt with this subject. We refer the reader to the above reviews. As a typical example, [69] single wall carbon nanotubes (SWCNT) were modified by several diazonium salts (R-Ar- $\left.\mathrm{N}_{2}{ }^{+}, \mathrm{R}=\mathrm{Cl}, t-\mathrm{Bu}, \mathrm{COOCH}_{3}, \mathrm{NO}_{2}, \mathrm{COOH}\right)$. This was achieved by in situ preparation of the diazonium salt, in acetonitrile, in the presence of $t$-butylnitrite, by and the spontaneous grafting of the dispersed SWCNT by heating at $45^{\circ}$. When $\mathrm{R}=\mathrm{Cl}$, it was possible to measure the degree of functionalization: 2.2 chlorine atoms per 100 carbon atoms. An efficient characterization of the grafting is provided by the Raman spectrum of the modified SWCNTs that presents an intense D-band corresponding to an increased number of $\mathrm{sp}^{3}$ carbons.

Graphene nanoplatelets. Graphene is a two-dimensional nanomaterial, described as a 
monolayer of carbon atoms arranged into a honeycomb network. [70-71] Since its rediscovery and isolation in 2004, it has raised a lot of interest in particular for drug delivery system applications thanks to its unique characteristics: good stability, huge specific surface area and superior mechanical properties. However, its large aromatic structure results in hydrophobic properties, which favor irreversible aggregation, limit its solubility in polar solvents and strongly compromise its further engineering and applications. The surface functionalization of graphene is needed to improve its solubility, storage duration as well as biocompatibility. Different forms of graphene can be modified on the basal plane and edges; exfoliated graphene, graphene oxide ( $\mathrm{GO}$, where part of the carbons is oxidized, and therefore rehybridized into $\mathrm{sp}^{3}$ ), [72] reduced graphene oxide ( $\mathrm{rGO},[73]$ by reduction of GO). The control of surface chemistry was shown to play a key role on the toxicological profile of graphene nanomaterials. [70] In particular, soluble and individually dispersed graphene nanoflasks could be less toxic that graphene aggregates. To control surface chemistry, graphene can be easily reacted with diazonium salts on its surface and edges, yielding nanomaterials that can be used as drug nanocarrier platforms [74] but also for electronics and energy storage.

Gold NPs. Au nanoparticles are generally produced by the classical Turkevitch [75] and Eah [76] methods (reduction of $\mathrm{AuCl}_{4}{ }^{-}$by citrate and borohydride, respectively) and can be subsequently modified spontaneously by diazonium salts through a covalent bonding. However, it is possible to obtain directly gold nanoparticles functionalized with aryl groups by simultaneous reduction of a metal salt and a diazonium salt. In this approach, the gold anion $\mathrm{AuCl}_{4}{ }^{-}$can be the counter ion of the diazonium salt, for example: [4- $\left.\mathrm{NO}_{2}-\mathrm{C}_{6} \mathrm{H}_{4} \mathrm{~N} \equiv \mathrm{N}\right] \mathrm{AuCl}_{4}$.[77] Gold nanoparticles are formed by reduction of both the diazonium salt and $\mathrm{AuCl}_{4}{ }^{-}$with borabicyclo[3.3.1]nonane (9-BBN). This produces gold nanoparticles directly modified by nitrophenyl groups. This surface modification prevents their agglomeration. Similar NPs but capped with phenylcarboxylic groups and bovine serum albumin (BSA) were prepared in view of theranostics applications (Figure 4).[78]

Another approach for the functionalization of Au NPs by diazonium salts takes advantage of so called "hot electrons", that can be produced on structured gold surfaces or nanoparticles by photochemical excitation of surface plasmons. These hot electrons, which are produced in nanoscale area of maximum near field enhancement, are able to reduce locally diazonium salts. The site-selective hot-electron mediated reduction of diazonium salts generates aryl layers attached covalently and regioselectively on gold nanostructures. [38, 79-80] This was used for the modification of gold surfaces including nanorods, nanotriangles,[81] nanodisks [38] or gold coated fibers.[82] For example, when nanorods are irradiated by a polarized laser beam along their long axis, modification occurs mainly on the tips of the nanorods. The same approach was performed on nanodisks, using successive irradiations under perpendicular directions, with two different diazonium salts. This two-step site-selective process yielded nanostructures patterned by two different types of functional polyaryl layers. In addition, underivatized $\mathrm{Au}$ NPs can be bonded to thermo-responsive polymer brushes grown by controlled radical polymerization, using initiators derived from diazonium salts, first grafted on macroscopic gold surfaces.[83]

Many other nanoparticles have been modified with diazonium, Cu,[84] Ag, [85] Pt, [86] Si [87] and black P, [88-90] oxides such as $\mathrm{CeO}_{2}$ [61] as well as core-shell nanoparticles such as magnetic Fe@C,[91] and Cr@Pt.[92] This functionalization strategy based on aryl diazonium 
salts thus opens new horizons in NP surface chemistry.

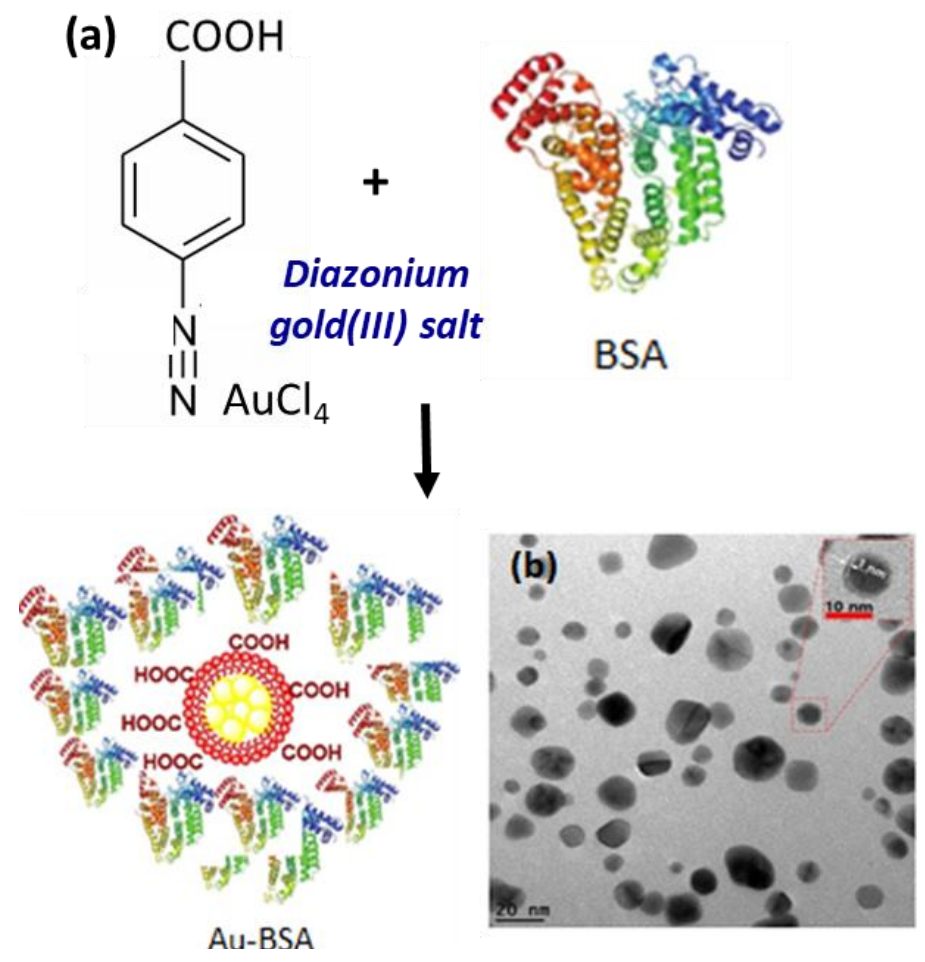

Figure 4. (a) Synthesis of Au NPs directly capped with aryl groups derived from diazonium salts and coated with BSA. (b) TEM image of Au NPs-BSA bioconjugates. The inset evidences the presence of the BSA layer. Reproduced with permission from ref. 78. Copyright, 2018 Elsevier.

\section{BIOCOMPATIBILITY OF NANOPARTICLES}

Many reviews are dedicated to the biocompatibility and in vivo fate of NPs, which complexly depends on the size, shape, architecture (curvature, softness) and composition of NPs, as well as their aggregation status in the different biological environments they successively encounter, i.e. blood compartment, plasma proteins, extracellular matrix, cell surface and intracellular compartments.[93] A critical aspect is the interaction of NPs'surface with endogenous proteins, forming the so-called protein corona, which strongly depends on the strategy of surface functionalization and on the size of NPs. Ultrasmall NPs $(<4 \mathrm{~nm})$ are less susceptible to protein corona.[94-95] Functional groups and targeting agents at the surface of NPs must resist the competitive interactions with proteins which may detach them from the particles or hide the targeting groups and compromise their transport, targeting, immune escape and cell uptake capabilities. Another key point of the NPs biocompatibility is their degradability or long-term persistence in the body [96]. Iron oxide nanocrystals can be degraded by cells within the harsh acidic ( $\mathrm{pH} 4.7)$ environment of lysosomes and iron is recycled by endogenous ferritin proteins, however the kinetic of degradation might depend on the initial NPs functionalization[97-98] Extracellular and lysosomal enzymes involving reactive oxygen species can also degraded carbon nanotubes and graphene.[99] More surprisingly, it was recently demonstrated that gold NPs, that were generally thought to be inert, 
can also dissolve within lysosomes and recrystallize into self-assembled biomineralized nanostructures called aurosomes.[100] Despite intensive research in this field, the way surface functionalization of NPs can preserve their targeting capability and control their biodegradability and long term fate in the body is not fully understood.

\section{FUNCTIONALIZATION OF NPS BY ARYLDIAZONIUM SALTS FOR DRUG DELIVERY APPLICATIONS}

The use of nanoparticles for drug delivery has been the subject of intense research and a large number of references can be found under this heading. [101-103] This application requires the nanoparticle to be biocompatible, biodegradable and non-toxic. Moreover, it has to overcome a number of biological barriers and escape clearance mechanisms before releasing the drug at a specific location. This can be achieved by enzymes, $\mathrm{pH}$ changes, or by reduction. The specificity and kinetics of drug release are expected to increase safety and efficacy and reduce side effects by comparison with classical ways of drug delivery.[104] Thanks to these advantages, some nanoparticle-based drug delivery systems have reached the market or are under clinical trials.[105] Besides, multifunctional features can be incorporated into one ideal drug nanocarrier: for example, drug cargo, imaging agents or other molecules can be encapsulated into every single nanocarrier or/and covalently linked to its surface. Characteristic groups can also be grafted on NP surface to be specifically recognized by target cells or tissues and to reduce non-specific interactions before the nanocarrier reaches its desired destination. Examples of use of diazonium salts to develop drug delivery systems are presented afterwards. The drug delivery nanocarrier candidates will be divided into three categories: i) carbon-based NPs, ii) metallic and oxide NPs and iii) virus-based nanocages. For each nanomaterial category, we describe its advantages and drawbacks as drug delivery system and present examples of NPs modified by diazonium salt chemistry, emphasizing the role of this surface functionalization agent for the construction of nanocarriers.

\section{1 Carbon-based nanocarriers}

In recent years, many nanometric forms of carbon have been exploited to create innovative composite carriers. Carbon-based nanomaterials include graphene, fullerenes and nano-onions, carbon nanotubes and nano-scale diamond particles. These nanocarriers were used in drug delivery system applications thanks to their large surface area, that allows high drug loading. $[74,106]$ In this section, we will focus on graphene derivatives and nanoscale diamond particles.

Graphene derivatives. As an example, a covalent multifunctional graphene platform was equipped with three different groups for anticancer therapy as shown in Figure 5a. [107] These groups were bonded in a sequential manner. First, in order to detect the nanoplatelet in the cell, a fluorescent label (indocyanine green, ICG) was covalently bonded; second, folic acid (FA) that permits to target cancer cells was attached at the extremity of a tethered polyethylene glycol (PEG) chain that plays two important roles: it increases graphene water dispersibility and improves its biocompatibility; third, doxorubicine (DOX), an anticancer drug that should be delivered to the cancer cell, was bonded to the graphene plate. Bonding of these three groups 
was achieved through an extensive use of diazonium chemistry: graphene was reduced with $\mathrm{KC}_{8}$ and reacted with three different 4-amino protected monodiazonium salts deriving from p-aminobenzylamine. The obtained nanomaterials (mfG/PEG- FA/ICG/DOX, mFG = multifunctional graphene) showed excellent anti-cancer ability, based on both chemo- and photothermal therapy. Interestingly, the combination of these properties resulted in synergetic effects improving anti-cancer efficacy, as observed on the cell viability experiments displayed in Figure 5b.

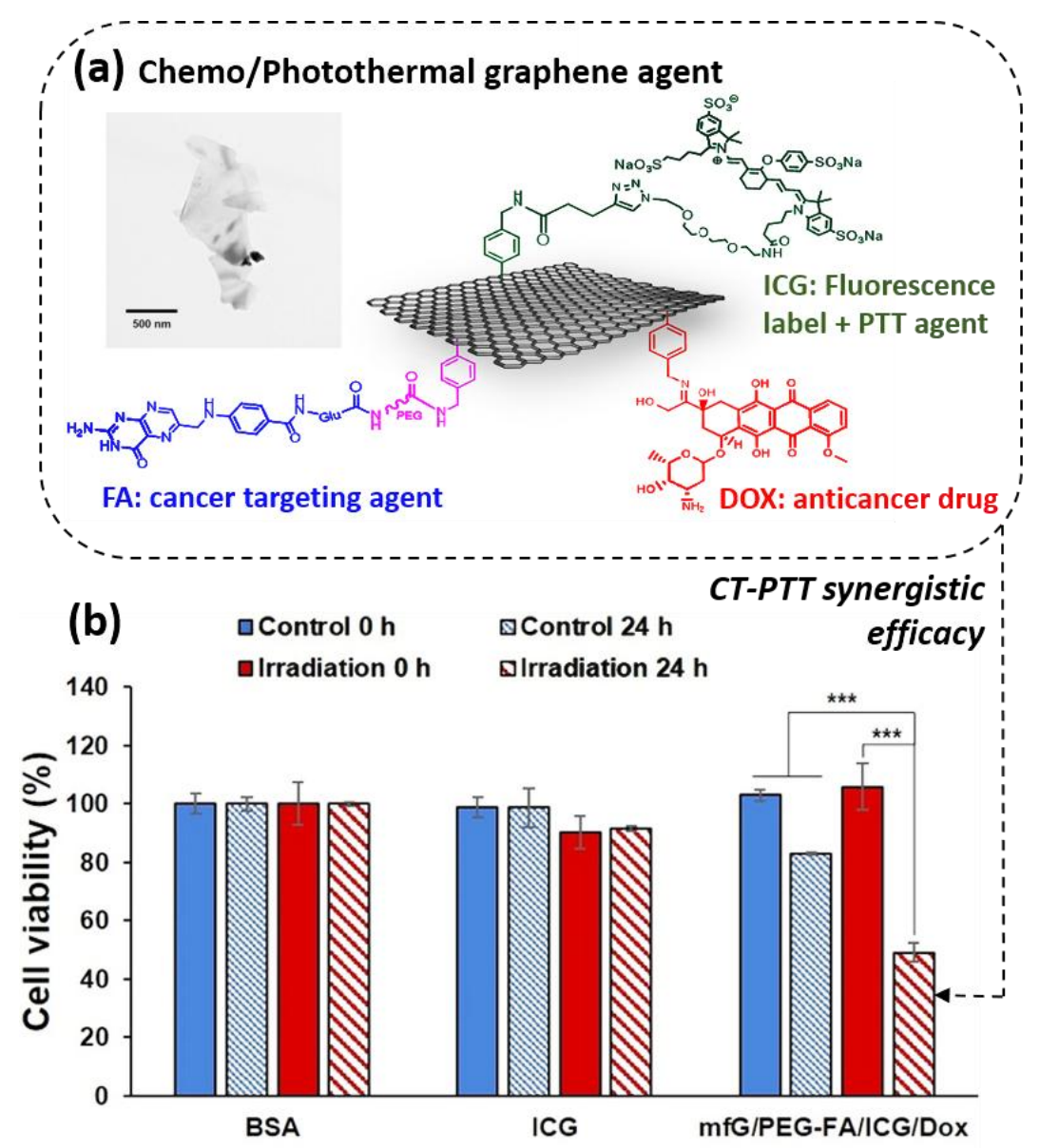

Figure 5. (a) Illustration of chemo/photothermal (CT/PTT) graphene agent: mfG/PEG- FA/ICG/DOX, where $\mathrm{mFG}$ stands for multifunctional graphene. Inset: TEM image of mfG/PEG- FA/ICG/DOX after dispersion in water (scale bar $=500 \mathrm{~nm}$ ). (b) Cell viability assays of HeLa cells after incubation with BSA $\left(20 \mu \mathrm{g} \cdot \mathrm{mL}^{-1}\right)$, ICG $\left(0.9 \mu \mathrm{g} \cdot \mathrm{mL}^{-1}\right)$ and $\mathrm{mfG} /$ PEG- FA/ICG/DOX $\left(20 \mu \mathrm{g} \cdot \mathrm{mL}^{-1}\right)$, during 0 and $24 \mathrm{~h}$ with or without laser irradiation at $785 \mathrm{~nm}$ laser $\left(8 \mathrm{~W} \mathrm{~cm}^{-2}\right)$. Reproduced with permission from ref. 107 . Copyright, 2020 Wiley.

In another example, graphene NPs modified by carboxyl groups using diazonium salt chemistry were coupled to initiators of reversible addition fragmentation transfer (RAFT) polymerization to design $\mathrm{pH}$-sensitive, mechanically strong and thermally stable graphene/poly(acrylic acid) hydrogel composites.[106] DOX could be loaded within the hydrogel composite and released in vitro at $\mathrm{pH} 7.4$ (a neutral environment mimicking that of intestine, $80 \%$ in 10 hours), faster than at $\mathrm{pH} 2$ suggesting that the nano-platform could be used for $\mathrm{pH}$-controlled drug release in the neutral intestine environment. Similarly, a reduced 
graphene oxide platform was modified with aryl diazonium salts $\left({ }^{+} \mathrm{N}_{2}-\mathrm{C}_{6} \mathrm{H}_{4}-\mathrm{COOH}\right)$ to give surface carboxyl groups. [108] This modification permits, after sonication, to obtain graphene flakes less than 2 layers thick, as observed in TEM image Figure 6. The resulting functionalized rGO was further modified by (i) polyethyleneimine (PEI) to improve water solubility and release the drug after a $\mathrm{pH}$ change, and (ii) folic acid (Figure 6a) to target overexpressed- folic acid receptor on the surface of CBRH7919 cancer cells. Drug loading and release properties from the functionalized rGO sheets were evaluated using DOX as model anticancer drugs. The drug delivery vehicle (rGO-PEI-FA) was found to be biocompatible, causing few normal liver cells death at $10 \mathrm{mg} \mathrm{L}^{-1}$. Moreover, the cancer cell viability studies (Figure 6b) revealed that the drug loaded rGO-PEI-FA/DOX is more efficient for cancer cell apoptosis with respect to DOX, which is a valuable feature for cancer therapy.
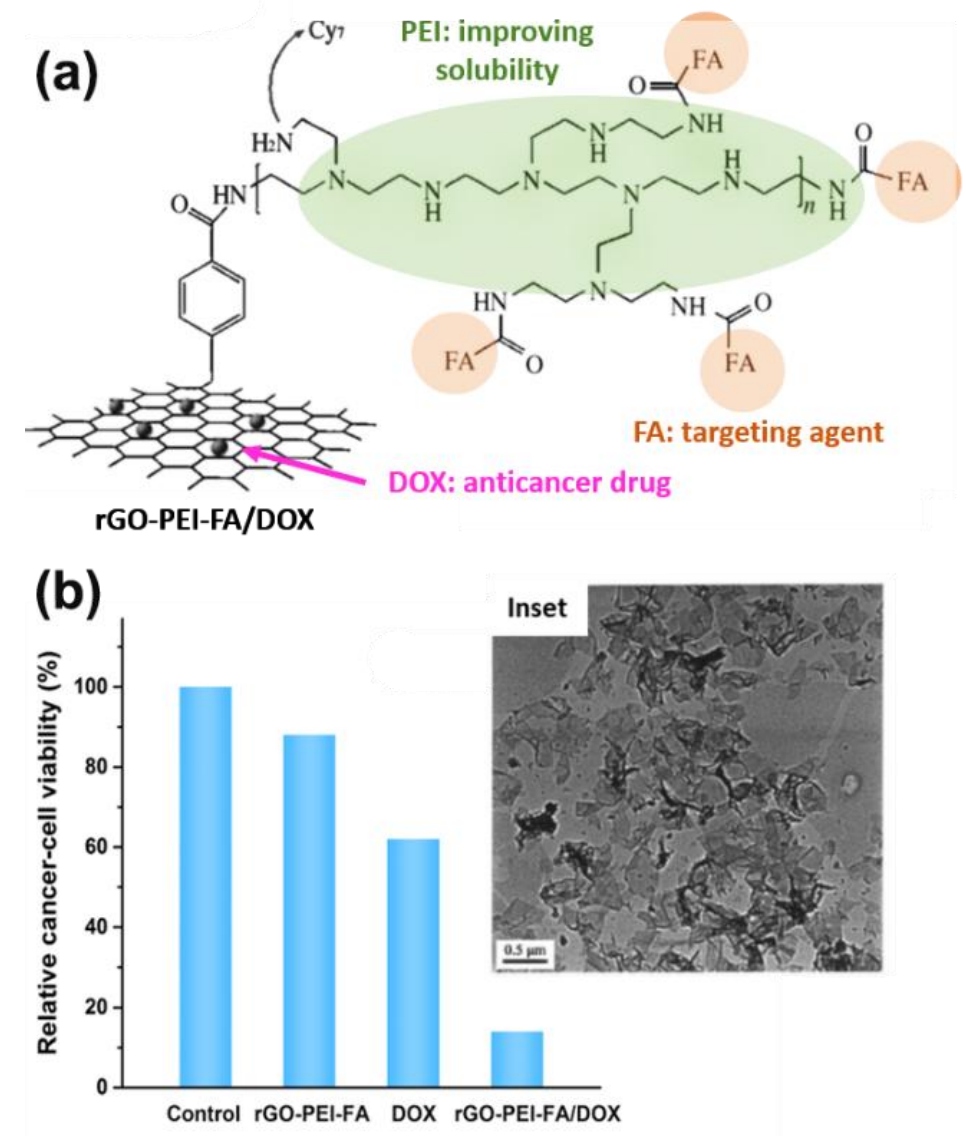

Figure 6. (a) Illustration of graphene-based drug delivery system: rGO-PEI-FA/DOX, with rGO = reduced graphene oxide, FA = folic acid, $\mathrm{PEI}=$ polyethyleneimine, $\mathrm{DOX}=$ doxorubicine. Inset shows TEM image of aryl diazonium grafted rGO sheet $\left(\mathrm{rGO}-\mathrm{C}_{6} \mathrm{H}_{4}-\mathrm{COOH}\right)$, scale bar $=500 \mathrm{~nm}$. (b) Cell viability tests of CBRH7919 cancer cells after incubation with $\mathrm{rGO}-\mathrm{PEI}-\mathrm{FA}\left(\mathrm{FA}=10 \mathrm{mg} \cdot \mathrm{L}^{-1}\right)$, DOX (1 $\left.\mathrm{mg} \cdot \mathrm{L}^{-1}\right)$ and $\mathrm{rGO}-\mathrm{PEI}-\mathrm{FA} / \mathrm{DOX}\left(\mathrm{FA}=10 \mathrm{mg} \cdot \mathrm{L}^{-1}\right.$, DOX $\left.=1 \mathrm{mg} \cdot \mathrm{L}^{-1}\right)$. Reproduced with permission from ref. 108. Copyright, 2012 Wiley.

Q-Graphene NPs, noted as Q-G, which are high-volume three-dimensional spheres, close relatives of fullerenes, were also exploited, in combination with diazonium salts, for drug delivery. Particles of $\sim 80 \mathrm{~nm}$ size (see TEM image Figure 7a) with a large surface area (55 
$\mathrm{m}^{2} / \mathrm{g}$ ) were first functionalized with carboxylic acid groups by oxidation in $\mathrm{H}_{2} \mathrm{SO}_{4} / \mathrm{HNO}_{3}$, in order to impart electrostatic repulsive forces between negatively charged nanoparticles. [109] Then, the solubility of Q-Graphene was further enhanced by sulfonation through reaction with the diazonium salt of sulfanilic acid. After coupling to (i) a fluorescent dye (RBITC) for tracking cellular internalization of the nanoparticles, (ii) hyaluronic acid (HA), a molecule with high affinity for CD44 receptors expressed on the surface of cancer cells (A 459) and, finally (iii) DOX adsorbed via $\pi-\pi$ stacking and hydrophobic interactions, the internalization and release of DOX from the modified Q-Graphene (HA-Q-G-RBITC/DOX, see illustration Figure 7a) was probed by fluorescence. The nanoparticles were effectively internalized by HA-positive A549 cells through HA-mediated cellular endocytosis. Moreover, they exhibited high efficiency in targeted drug delivery to cancer cells, as observed on the cell viability experiments Figure $7 b$.
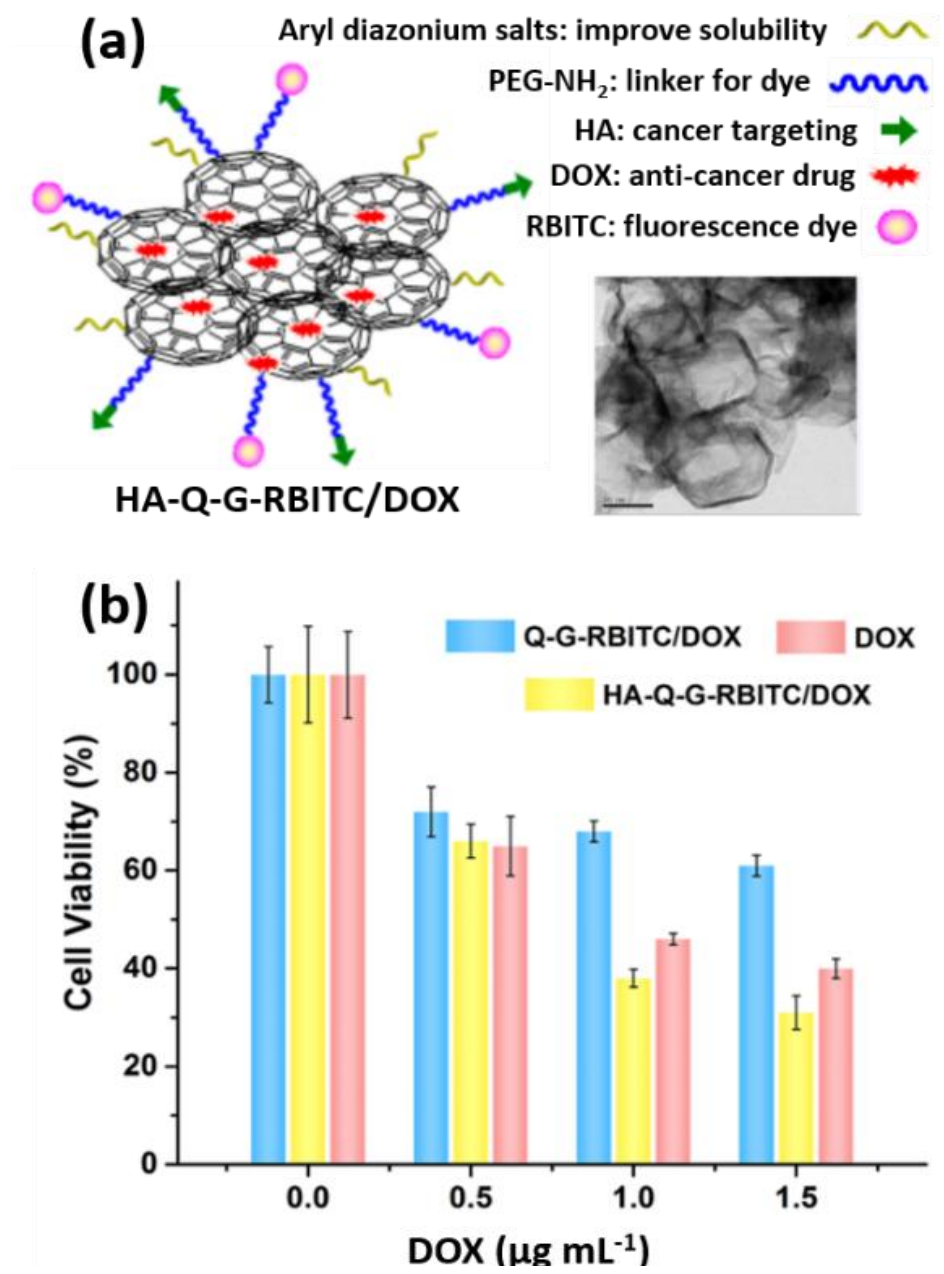

Figure 7. (a) Illustration of the functionalized Q-Graphene HA-Q-G-RBITC/DOX as drug carrier for killing cancer cells. Inset: TEM image of Q-Graphene (scale bar $=50 \mathrm{~nm}$ ). (b) Cytotoxicity of Q-G-RBITC/DOX, HA-Q-G-RBITC/DOX and DOX against A549 cell. Data extracted from ref. 109. Copyright, 2016, American Chemical Society.

Nanoscale diamonds. Nanodiamonds are also members of carbon-based nanomaterial family. They gained worldwide attention due to their inertness, inexpensive synthesis as well as non-toxicity. These properties of NDs have created opportunities for devising tissue 
engineering scaffolds, surgical equipment, and other biomedical applications.[110-111] Classical nanodiamond surface functionalization approaches based on physical adsorption present drawbacks such as weak bioconjugation ability and undesirable agglomeration. To overcome these limitations, aryl diazonium salt chemistry is considered nowadays as a simple and effective method to modify nanodiamonds, enabling the formation of robust linkages between surface carbon atoms and aryl rings with various substituents. The strongly bounded functional aryl groups could be used to initiate atom transfer radical polymerization (ATRP) from nanodiamond surface, yielding hairy diamond nanoparticles with poly(methacrylic acid) grafts that can be further decorated by bovine serum albumin (BSA).[112] In another example, a laser treatment was performed on diamond nanoparticles prior to their functionalization by diazonium salts in order to generate $\mathrm{sp}^{2}$ surface carbon atoms, exhibiting a higher reactivity than the initial diamond $\mathrm{sp}^{3}$ atoms.[113] The laser-activated nanodiamonds were further modified with both amino and carboxyl-terminated aryl groups resulting in amphiphilic products that can be coupled to biologically active molecules, such as Ketoprofen and a 6-aminohexanoic acid derivative. The nanohybrids could also incorporate folic acid and fluorescent markers, allowing NP targeting and tracking. Although few examples of nanodiamond modification by aryl diazonium salts have been reported up till now, the simple functionalization processes of this approach associated with the wide range of available functional groups, makes it attractive for the development of nanodiamond-based drug carriers.

\subsection{Metallic and oxide nanoparticles}

Among metallic and oxide nanoparticles, gold and iron oxide NPs have exhibited prominent potential in delivering drugs to specific sites and have been the subject of recent biomedical studies targeting cancer treatments. [114]

Gold nanoparticles. The major interest of Au NPs for drug delivery applications is their chemical stability and relative biocompatibility. Moreover, surface modification of Au NPs, through the formation of Au-C, Au-N and Au-S bonds is relatively easy to perform in order to improve their colloidal stability and to add surface functionalities. [115] Additionally, the feasibility of synthesizing Au-DNA, Au-protein and Au-antibody conjugates contributes to targeting specificity. As stated in Section 3, Au NPs are easily modified by diazonium salts. For example, remarkably stable hemocompatibility of Au NPs can be achieved by surface modification with BSA conjugates, via aryl diazonium salts. [78] Such hemocompatible NPs could be used as valuable nanotools in view of intravenous drug delivery. In this work, BSA conjugated $\mathrm{Au}$ NPs were generated by co-reduction of $\mathrm{AuCl}_{4}{ }^{-}$and aryl diazonium salts bearing - $\mathrm{COOH}$ functional groups, using 9-borabicyclo(3.3.1)nonane as reducing agent, in the presence of BSA. The resulting nanoplatforms (Au NPs-BSA, cf. Figure 4a-b) demonstrated a large encapsulation efficiency, reaching $c a .90 .0-94.6 \%$ at physiological $\mathrm{pH}$ values and a high resistance to acidic, neutral and basic environment. Moreover, the hybrid NPs exhibited great hemocompatibility with human red blood cells after BSA congution. After $24 \mathrm{~h}$ of incubation with Au NPs-COOH without BSA, $4 \%$ of blood cells were hemolyzed whereas only $1.5 \%$ of cells were hemolyzed when incubated with Au NPs-BSA conjugates. 
Iron oxide nanoparticles. Iron oxide nanoparticles are biocompatible, non-toxic and possess unique magnetic properties.[116] They are sensitive to external magnetic field and can be used as "smart" drug nanocarriers.[117] Besides, they can be used as contrast agents for magnetic resonance imaging (MRI) [118] helping to monitor therapeutic responses.[119] Diazonium salt chemistry has been applied to provide robust and stable linkages between iron oxide surface and coatings. For example, iron oxide nanoparticles were synthetized by mixing $\mathrm{FeCl}_{3}$ with $\mathrm{NaBH}_{4}$.[120] The obtained oxide NPs were simultaneously functionalized with phenylcarboxylic groups using diazonium chemistry, and noted $\mathrm{Fe}-\mathrm{COOH}$ NPs. They were further coated by a mixture of chitosan (e.g. Fe-COOH-CS NPs) and chitosan-grafted polylactic acid (e.g. Fe-COOH-CS-g-PLA NPs). This coating offers several advantages: (i) it prevents the aggregation of the coated iron oxide particles. (ii) it permits loading DOX and slowing down its release. Indeed, the encapsulation efficiency of DOX on Fe-COOH surface was about $20 \%$, but it could be significantly increased to $80 \%$ on Fe-COOH-CS and Fe-CS-g-PLA. Besides, while $80 \%$ of DOX was released from Fe-COOH within $10 \mathrm{~h}$, only $20 \%$ of DOX was released from Fe-COOH-CS and Fe-CS-g-PLA after 50h; (iii) it reduces the initial burst effect and increases the in vitro toxicity of the drug to HeLa cells. After $72 \mathrm{~h}$, the cell viability came close to zero with the coated iron oxide-drug loaded Fe-CS-g-PLA nanoparticles, compared to ca. $8 \%$ and $20 \%$ of cell alive after incubation with DOX loaded Fe-COOH-CS and $\mathrm{Fe}-\mathrm{COOH}$, respectively. Aryl diazonium salts substituted by oligo(ethylene oxide) chains terminated by an iniferter initiator were also covalently grafted on magnetic NPs to activate the growth of poly(methacrylic acid) chains.[121] This synthetic strategy resulted in the formation of $\mathrm{pH}$-sensitive polymer-coated magnetic NPs, paving the way to magnetic-driven targeting and $\mathrm{pH}$-controlled drug release systems.

\subsection{Virus-based nanocarriers}

Virus-based nanocarriers have become attractive platforms for drug delivery application. In this section, we will discuss specific virus-like particles functionalized by diazonium salts. Viruses have protein coatings called capsids, used for viral nucleic acid storage. For most viruses, their capsids can self-assemble into a cage-shaped architecture to form virus-like particles without any genetic substances. Virus-based nanocarriers are highly promising thanks to their robust structure, various shapes and sizes (ranging from $10 \mathrm{~nm}$ to micron).[122] Besides, each virus-based nanocarrier is identical to the other one, resulting in a homogeneous platform, whereas this quality is hard to obtain with other synthetic drug delivery systems.[123] Concerning inherent immunogenicity issues, different studies have demonstrated that selected virus-based particles are non-toxic and appropriate for biotechnological fields.[124] Suitable modification procedures are needed to functionalize virus-based nanocages with drug delivery relevant molecules. External modifications of the capsids generally consist in grafting specific ligands whereas interior modifications focus on encapsulation of drug cargo, imaging agents or other molecules. Once activated by specific receptors or under other conditions, virus-based NP degradation and disassembly occur and result in cargo release at the aimed location. As indicated above, diazonium salts can react with amino acids such as tyrosine, histidine and lysine through electrophilic substitution. Among them, tyrosine is the most commonly used amino acid for chemoselective modification of proteins. Tyrosine 85, located at the interior surface of MS2 capsids, was coupled with fluorescent dye-labelled diazonium salt, as 
illustrated in Figure 8. This diazonium coupling reaction allowed grafting 50-70 dyes within each virus-based nanoparticle, demonstrating the possibility to encapsulate large "drug-like" molecules within the cargo.[125]
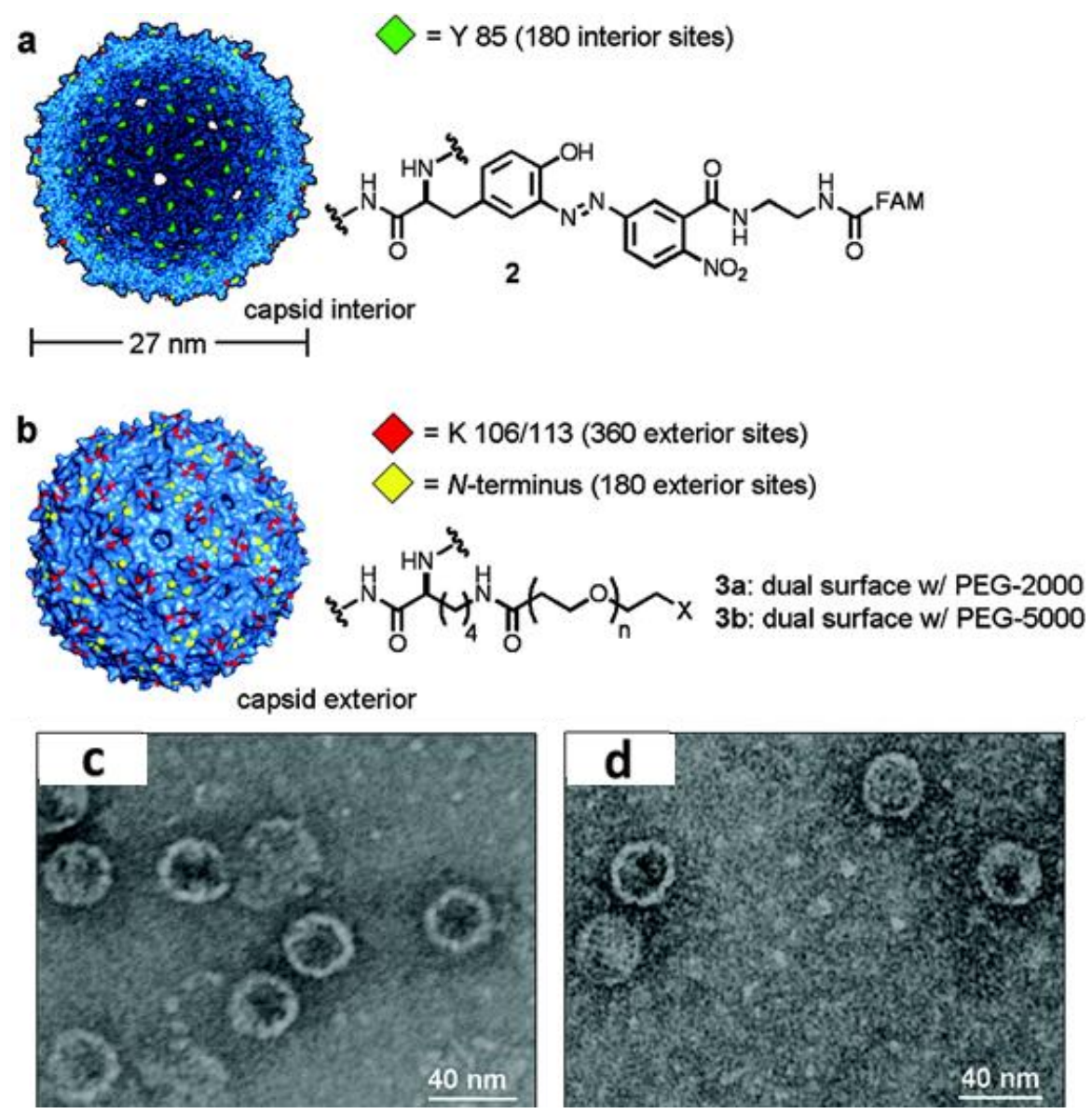

Figure 8. Dual surface functionalization of MS2 capsids. (a) The interior surface of the capsid was modified by coupling tyrosine 85 with p-nitroaniline diazonium derivatives, bearing large dye conjugates. (b) The exterior of the capsid was modified by the reaction between the accessible amino groups (from lysines and the N-terminus) and PEG-NHS esters. (c, d) Typical TEM images of the modified capsids after staining with $\mathrm{UO}_{2}(\mathrm{OAc})_{2}$. Reproduced with permission from ref. 125. Copyright, 2007 American Chemical Society.

Similarly, the surface of tobacco mosaic virus (TMV), a rod-shaped plant virus which is $300 \mathrm{~nm}$ in length and $18 \mathrm{~nm}$ in diameter, can be modified by diazonium salts and click chemistry. TMV comprises 2130 identical coat proteins that assemble into rod-like helical structures around a single strand of RNA. Coupling of 3-ethynylbenzene diazonium salt with tyrosine permits the incorporation of a terminal alkyne group. Then, via a click chemistry reaction based on copper-catalyzed azide-alkyne cycloaddition (CuAAC), the alkyne can be conjugated with a wide variety of small molecules such as coumarin and biotin, or with peptides and polymers.[126] By changing the final substituent, it is possible to control the adhesion of TMV on a glass surface. The same reaction was used to modify the surface of TMV with phosphate groups to induce calcium incorporation into bone marrow stem cells (BMSCs). Gene regulation during BMSC differentiation on TMV and TMV-phosphate induced changes in expression of osteospecific genes (osteocalcin, osteopontin and runx2). 
This approach provides a promising way to design a novel virus-based drug delivery system to treat bone defect. In another recent publication, spherical nanoparticles derived from TMV rods via heat transformation, could be conjugated to biotin by click chemistry and then loaded with DOX either by encapsulation or covalent attachment, to target and kill breast cancer cells. [123]

\section{FUNCTIONALIZATION OF NPS BY ARYLDIAZONIUM SALTS FOR NANO-BIOSENSORS}

Generally, a biosensor $[42,127-132]$ consists of two parts: the recognition probe and the transducer substrate. The recognition probe should identify and bind target analytes with the highest possible selectively and the transducer should transform the biometric events into physical signals, with a high amplification ratio to be received and analyzed. An ideal biosensor should have high selectivity and sensitivity to allow measurements in complex environments. It should also afford real-time detection of target analytes. A key factor in designing high-performance sensors is the selection of a suitable coupling agent to achieve stable immobilization of bioreceptors onto the surface of the transducer substrate. As they provide a strong covalent bonding with the substrate, diazonium salts contribute to the stability of biosensors.[133] In addition, they offer a high degree of flexibility thanks to the 4-substitution that permits many sensing molecules to be attached at this position. This advantage makes diazonium salts a promising coupling agent for the design of new generation biosensors. The high specific surface area of nanomaterials permits to attach a large amount of sensing molecules, which is beneficial to increase the detection limit of the biosensor. We describe here different types of biosensors prepared using aryl diazonium salts, based on i) molecularly imprinted polymers (MIPs), where a polymeric architecture is specially designed to be selective and specific of analytes, ii) surface confined biomolecules exhibiting high affinity with the target analytes and iii) vertically-aligned carbon nanotubes used to probe the intracellular medium.

\subsection{MIP biosensors}

Molecular imprinting [134-136] is based on monomer polymerization and cross-linking in the presence of the target analyte. After extraction of the imprinted analytes, the MIP matrix exhibits nanocavities that are highly specific for recognition of analytes.[137] By combining aryl diazonium salt chemistry and iniferter polymerization method, gold nanorods modified by molecularly imprinted polymer shells, via robust covalent Au-C bonds could be elaborated. Gold nanorods present remarkable optical properties based on localized surface plasmon resonances (LSPR). Excitation of LSPR by an incident light yields a strong enhancement of the local electromagnetic field close to the NPs, which can be exploited for the detection of analytes by surface-enhanced Raman spectroscopy (SERS). The MIP-coated gold nanorods were shown to enable the label-free detection of folic acid (FA) down to $0.1 \mu \mathrm{M}$ concentration via SERS.[138] It is noteworthy that the detection of FA is a critical clinical and health issue as this molecule is related to a series of diseases such as mental devolution, heart attack and congenital malformation. Nanocomposite films were also prepared by immobilizing gold nanoparticles onto gold electrodes and by growing MIP layers at the surface. The gold 
electrodes were first modified with thiophenyl groups using diazonium chemistry, resulting in surface thiol groups able to bind Au NPs. The Au NPs were further modified by reaction with the diazonium salt of benzophenone to induce surface-initiated photopolymerization of methacrylic acid and ethylene glycol dimethacrylate, in the presence of dopamine, used as the template molecule. These sensing layers permitted the label-free detection of dopamine by square wave voltammetry, down to $0.35 \mathrm{nM}$ concentration.[139] Molecularly imprinted polymers were coupled as well to magnetic NPs to facilitate manipulation of the nanohybrids using an external magnet, including separation of the particles from the medium and consecutive washing steps. These MIP-coated NPs display hyperthermia properties when submitted to an alternative magnetic field; which can be used to release the analytes under heating due to the disruption of hydrogen bonds. Protein imprinting over magnetic NPs was performed using a multi-step strategy involving first the functionalization of iron oxide NPs by aryl diazonium salts prior to surface-initiated photopolymerization, in the presence of various proteins, such as green fluorescent protein, BSA, ovalbumin, and lysozyme. Despite the well-known fragility of proteins, this strategy successfully yielded core-shell NPs with a high loading of proteins entrapped at the surface. After removal of the trapped proteins, the nanohybrids were shown to enable the selective uptake of proteins with high adsorption capacities, opening promising perspectives for protein nanosensors.[140]

\subsection{Biosensors based on biological recognition}

Conventional diagnostic tools for antigens or antibody detection are based on sandwich bioaffinity assays [141-143] (sandwich assay as the analyte is "sandwiched" between two antibodies) such as enzyme-linked immunosorbent assay (ELISA). Although widely used, these approaches present a limited sensitivity, multistep sample processing and long diagnostic times. In this regard, nanotechnology may offer attractive alternatives to achieve ultrasensitive bioassays via amplified transduction of biomolecular recognition events, based on electronic or optical signals. As an example, graphene nanomaterials were used for the detection of various biomarkers in electrochemical immunosensors due to their specific surface area, good biocompatibility and high electrical conductivity. Complex biosensor structures based on graphene were prepared by exploiting diazonium salt chemistry, [144] as shown in Figure 9a. An Au electrode was first modified by amino phenyl groups derived from diazonium chemistry. The amino groups were then transformed to diazonium in order to bind Au NPs-decorated rGO nanosheets. The Au NPs were subsequently modified with two different groups, phosphorylcholine and carboxyphenyl (both attached to the Au NPs by diazonium chemistry) to prevent non-specific adhesion of proteins and to attach the analytes through formation of an amide bond. 


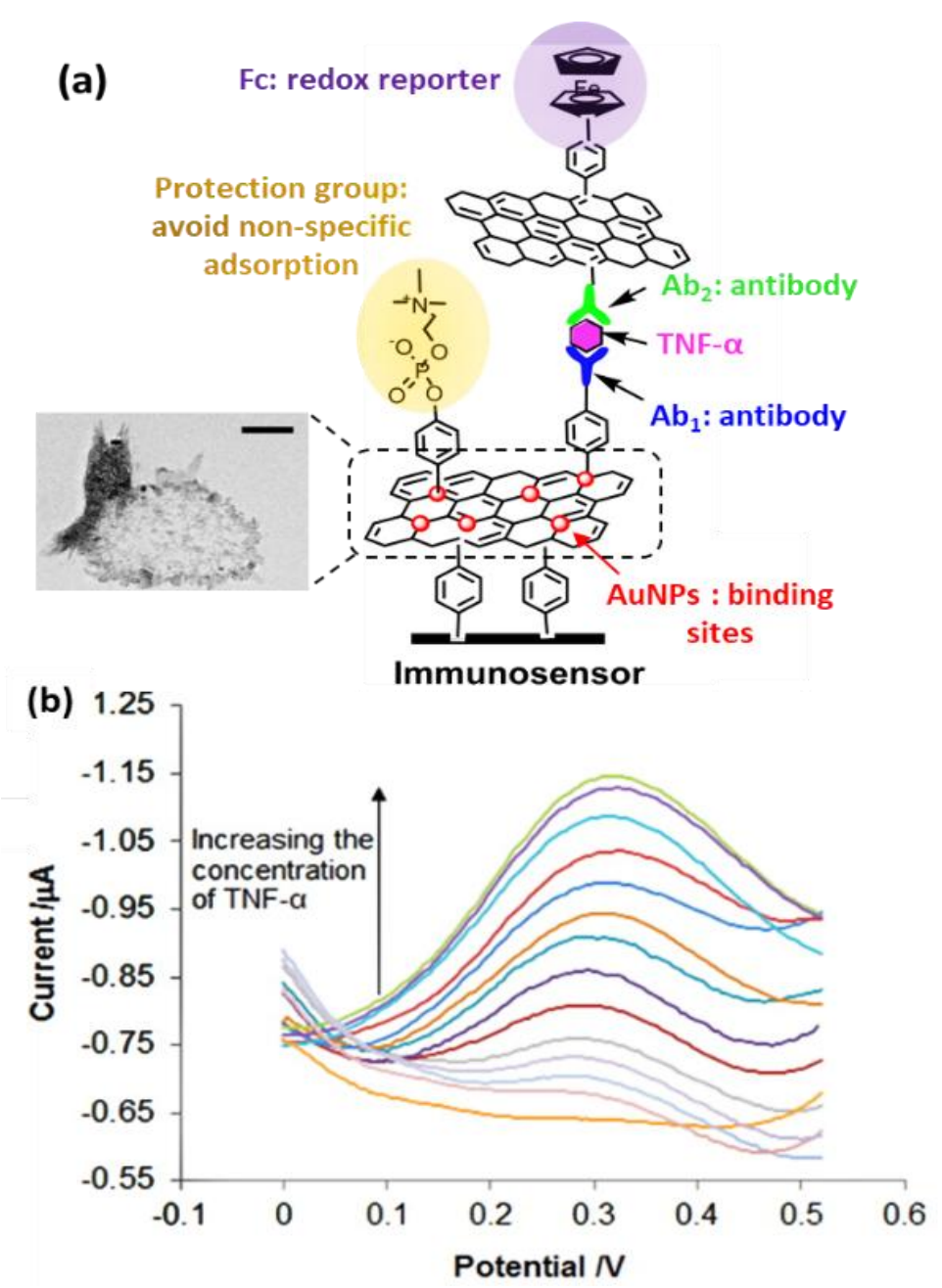

Figure 9. (a) Representative scheme of an electrochemical immunosensor based on graphene functionalized by diazonium salts, for the detection of TNF- $\alpha$. Inset: TEM image of rGO functionalized by aryl diazonium salts and AuNPs. Scale bar $=100 \mathrm{~nm}$. (b) Squarewave voltammetry curve for TNF- $\alpha$ detection on the immunosensor. TNF- $\alpha$ concentration was varied from 0 to $0.1,0.2,0.5,1,2,5,10,20$, 50, 80, 100, 150, and $200 \mathrm{pg} \cdot \mathrm{mL}^{-1}$. Reproduced with permission from ref. 144. Copyright, 2014, American Chemical Society.

The selected analyte was cytokine tumor necrosis factor-alpha (TNF- $\alpha$ ), responsible of a wide range of pathological and physiological processes. The reporter group was a rGO nanosheet equipped with i) a second antibody that recognizes the analyte and ii) a ferrocene group (attached to the graphene sheet by diazonium chemistry) that can be detected by electrochemistry. The prepared electrochemical immunosensor was successfully used for the detection of the tumor necrosis factor TNF- $\alpha$ over the range of $0.1-150 \mathrm{pg} \mathrm{mL}^{-1}$, in $50 \mathrm{mM}$ phosphate buffer at $\mathrm{pH} 7.0$ (Figure 9b). This proof-of-concept sensing platform can be transposed to the detection of a wide range of proteins, opening promising prospects for the elaboration of point-of-care devices in clinical applications. Calcitonin, a medullary thyroid carcinoma tumor marker, was detected by an immunosensor elaborated by immobilizing $\mathrm{Au}$ NPs and GO on a glassy carbon electrode via aryldiazonium salts chemistry. The transduction was achieved through the electrochemical detection of ferrocene attached to the graphene oxide nanoplatelets.[145] An immunosensor was also fabricated for the detection of clinically relevant levels of B-type natriuretic peptide (BNP) in human serum samples. These molecules 
are considered as biomarkers of biomechanical cardiac stress. Au NPs functionalized by capture antibodies were grafted on a screen-printed carbon electrode (SPCE) through aryl diazonium salt chemistry using 4-aminothiophenol, resulting in a high conductivity of the immunosensor and stability of the grafted biomolecules. The amperometric transduction was carried out by electrochemistry upon the addition of hydroquinone as electron transfer mediator and $\mathrm{H}_{2} \mathrm{O}_{2}$ as the enzyme substrate. This biosensor permitted the detection of BNP at a concentration 100 times lower than the established cut-off value for heart failure (HF) diagnosis.[146] Optical transduction based on SERS labels was reported for the detection of biomolecular analytes. Au NPs were functionalized by 4-aminothiophenol, the SH function acting as an anchoring group for gold NP surface. The amino function was transformed to diazonium salt to bind $\mathrm{p} 53$ proteins (a tumor marker). The nanoconjugates were then captured on a recognition surface modified by silane chemistry with azurin, a protein known to form stable complexes with human p53 protein. Due to the SERS effect provided by Au NPs, the Raman signal of the resulting sandwich system was strongly enhanced providing an easy means to selectively detect p53 proteins in human serum at low concentrations, with a detection limit of $500 \mathrm{fM}$. The proposed SERS-based sensing strategy offers interesting perspectives to monitor p53 levels in human serum for noninvasive and early tumor screening.[147]

\subsection{Electrical wiring of cells}

In a very different manner, a nanoelectrode was introduced within a cell to detect the presence of an analyte. To offer a suitable interface with cells, single-walled carbon nanotubes (SWCNT) were vertically aligned and covalently bonded to an ITO surface preliminary functionalized using the monodiazonium salt of p-phenylene diamine (Figure 10a).[148]
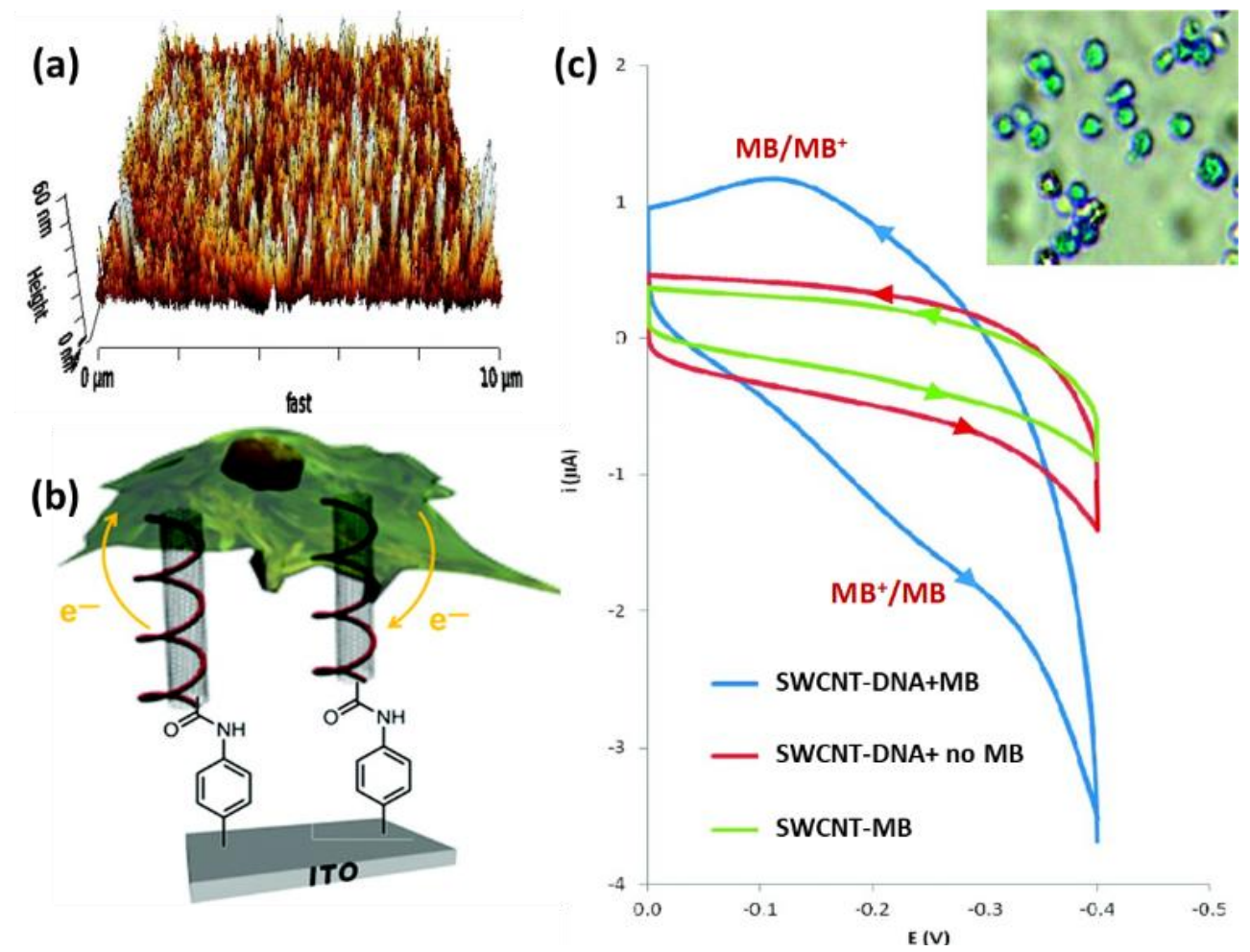

Figure 10. (a) AFM image of SWCNT modified ITO. (b) Representative scheme of vertically aligned SWCNT linked to the surface of ITO and wrapped with DNA (SWCNT-DNA), in order to be naturally 
taken up by a mouse macrophage cell. (c) Cyclic voltametric curves for SWCNT-DNA with (blue) and without (red) MB stain cells and SWCNT with MB stained cells (green). Insert: image of MB stained cells on SWCNT-DNA. Reproduced with permission from ref. 148. Copyright, 2013, American Chemical Society.

CNTs were then wrapped with DNA through ionic binding, in order to be naturally taken up by a mouse macrophage cell, as illustrated in Figure 10b. The vertical orientation of SWCNTs allowed them to enter the cytoplasm of the upward cells enabling the intracellular electrochemical sensing of methylene blue, chosen as a model redox active molecule. This molecule could be detected in stained cells on the SWCNT-DNA nanosensor while no signal was obtained in absence of stained cells or in SWCNT mixed with MB stained cells (Figure 10c). This innovative approach offers unprecedented opportunities for intracellular sensing.

\section{NANOTRACERS MODIFIED BY ARYLDIAZONIUM SALTS FOR BIOIMAGING}

Bioimaging [149-150] is a powerful tool for non-invasive medical examination. Unlike biosensors that provide physical signals, bioimaging technology can more intuitively provide $2 \mathrm{D}$ or 3D images of target analytes. Therefore, bioimaging is expected to play an important role in early-stage cancer diagnosis, image-guided surgery and identification of pathogens. A variety of effective imaging methods were developed, such as magnetic resonance imaging (MRI), positron emission tomography (PET), computed tomography (CT) and optical imaging. Fluorescence imaging has particularly attracted widespread attention due to its high sensitivity. For this imaging modality, the use of nanomaterials as contrast agents enables to obtain high-resolution images in living systems. Compared to conventional organic contrast agents, the main advantages of NPs rely on their brightness, absence of photobleaching and large multi-color imaging capabilities due to their narrow emission spectra. However, surface functionalization is a key challenge in the design of nanotracers for bioimaging applications. Indeed, it should achieve an appropriate balance between targeting moieties and stealth agents at the surface in order to control circulation times, active and passive accumulation as well as cellular uptake. Moreover, surface modification should prevent NPs aggregation and promote bioconjugation.[151] In this section, we will focus on bioimaging contrast agents based on nanomaterials modified by aryl diazonium salts.

An interesting example is the development of multimodal imaging probes based on multi-shell fullerenes, named carbon nano-onions. These nanomaterials exhibit interesting features for bioimaging such as small size (average diameters of $5 \mathrm{~nm}$ ), high biocompatibility and minimal systemic toxicity. However, their surface functionalization is a major challenge for active intracellular delivery. To meet this challenge, carbon nano-onions were modified by two different aryl diazonium salts, providing benzoic acid and alkyne surface functionalities for the subsequent covalent attachment of folic acid targeting agent and fluorescein imaging moiety (Figure 11a).[152] The interest of fluorescein relies on its high fluorescence quantum yield and low toxicity. The resulting nanohybrids exhibit strong brightness and photostability and are rapidly uptaken in cancer cell lines. Interestingly, the functionalized carbon nano-onions behaved as fluorescence and electron microscopy markers and could thus be visualized in late endosome cell compartments using a correlative approach with confocal and 
transmission electron microscopy (Figure 11b). The use of diazonium salt chemistry to functionalize the surface of carbon nano-onions thus allows guiding them in cellular environment and understanding their biological response, with new opportunities for imaging, targeting and diagnosis applications.
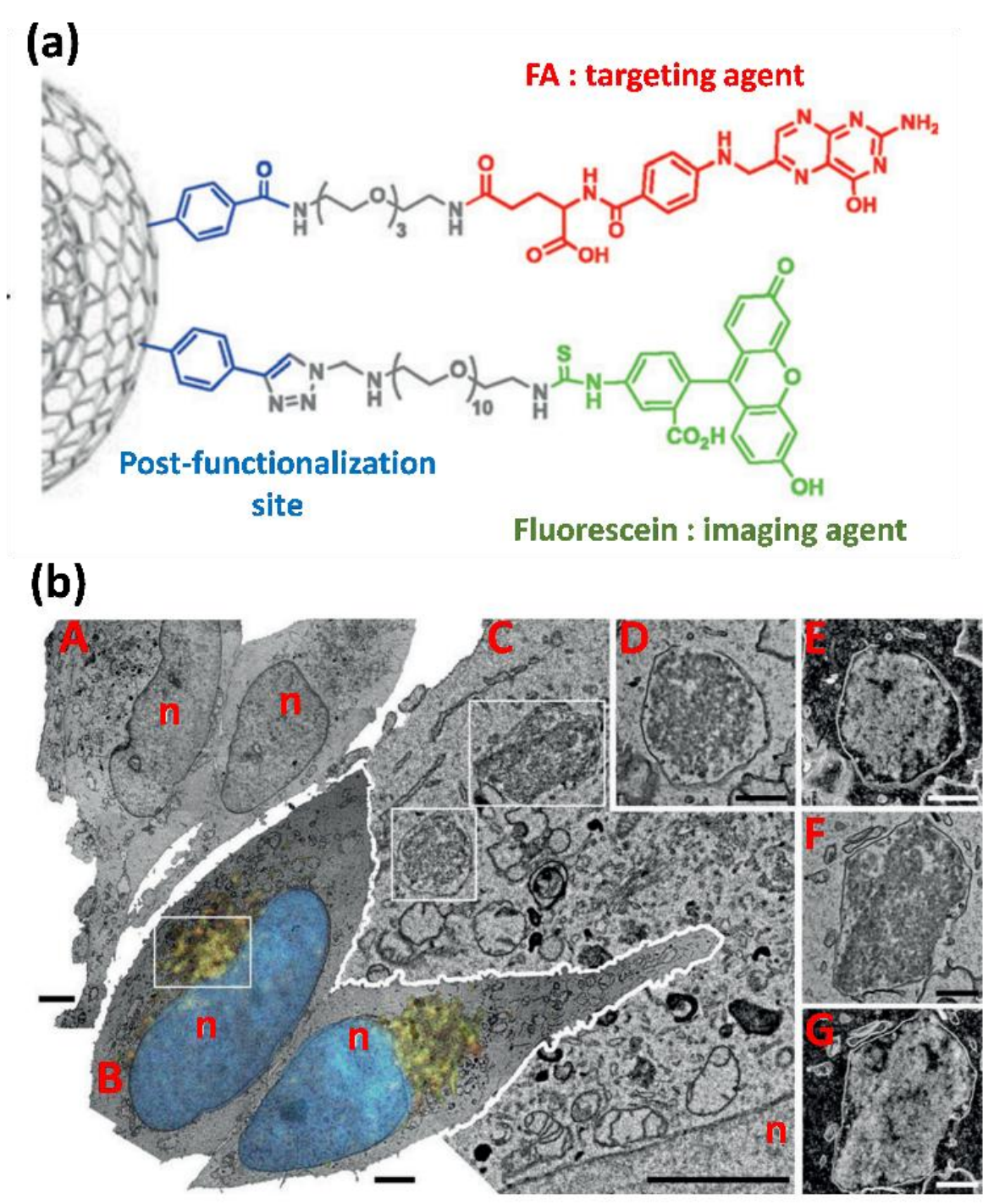

Figure 11. (a) Representative scheme of carbon nano-onions modified by diazonium salts; (b) Correlative light electron microscopy analysis of HeLa cells after uptake of the modified carbon nano-onions: A) TEM image at low magnification of two cells with internalized carbon nano-onion. B) Superimposed fluorescence and TEM images of cells revealing the presence of NPs inside the lysosomes. C) TEM image of the inset box in B. D-G) TEM images at higher magnification of the inset boxes in C. The label " $n$ " refers to the nuclei. Scale bars: A, B) $4 \mu \mathrm{m}$, C) $2.5 \mu \mathrm{m}, \mathrm{D}-\mathrm{G}) 0.5 \mu \mathrm{m}$. Reproduced with permission from ref. 152. Copyright, 2015, Wiley.

A new member of the family of two-dimensional (2D) materials has emerged these past years, based on atomically thin black phosphorous nanosheets. This biocompatible nanomaterial presents strong near infrared (NIR) absorption and high photothermal conversion efficiency. Moreover, it can degrade in aqueous media yielding nontoxic phosphate and phosphonate, which is particularly valuable for biomedical applications. However, despite 
great strides in the design of black phosphorous-based nanomaterials, their widespread use is hampered by their rapid degradation upon exposure under ambient conditions. To overcome this limitation, surface functionalization was proposed as a suitable strategy. [153] Particularly, surface modification of these $2 \mathrm{D}$ nanomaterials by aryl diazonium salts was explored to enhance their water and air stability and provide NIR fluorescence imaging capacities. A fluorescent dye, Nile blue, was converted into the corresponding diazonium salt to react with black phosphorous surface, imparting a strong NIR fluorescence and forming robust interfacial $\mathrm{C}-\mathrm{P}$ bonds enhancing NP stability (Figure 12a). The resulting nanohybrids were shown to exhibit good biocompatibility, valuable NIR fluorescence and photothermal characteristics in vitro. Moreover, they were successfully used for tumor visualization (see Figure 12d) and photothermal ablation under NIR irradiation, demonstrating large potentialities in light-activable multimodal nanoparticles for imaging-guided therapy.

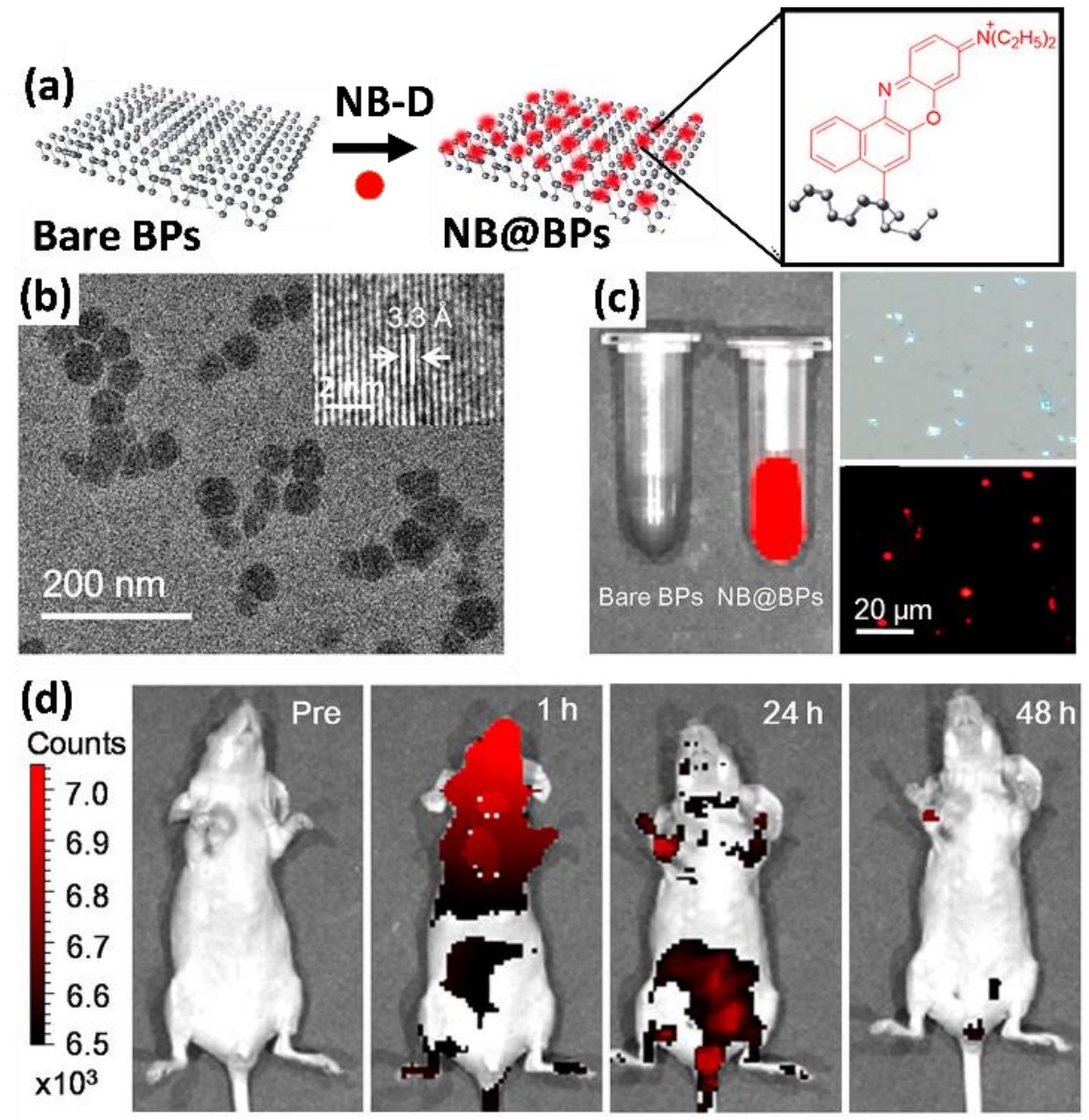

Figure 12. (a) Representative scheme of the preparation of theranostic probe based on Nile blue-modified black phosphorous (NB@BPs). (b) TEM image of NB@BPs with HR-TEM image in inset. (c) (Left) Macroscopic fluorescence image of bare BPs and NB@BPs, $\lambda_{\text {ex }}=570 \mathrm{~nm}$. (top right) Bright-field and (below right) fluorescence micrographs of NB @BPs. (d) In vivo fluorescence pictures of nude mice with MCF7 breast tumor (Pre) at different times (1h, 24h and 48h) after injection of NB@BPs via the tail vein. Adapted (a, c) and reproduced (b, d) with permission from ref. 153. Copyright, 2017, American Chemical Society.

Aryl diazonium salt chemistry were used to conjugate and label peptide-decorated 
polymeric micellar NPs by ${ }^{64} \mathrm{Cu}$ radionuclide for positron emission tomography (PET) imaging.[154] The polymeric micelles were first modified with peptide GE11, which displays a high binding affinity to epidermal growth factor receptor $\left(K_{d}=22 \mathrm{nM}\right)$, a well-known biomarker of proliferating and aggressive cancers. Their labeling with ${ }^{64} \mathrm{Cu}$ was performed through the in situ generation of ${ }^{64} \mathrm{Cu}$-complexes containing a diazonium salt group (Figure 13a), enabling chemoselective azo coupling to tyrosine residues of GE11 peptides present at the surface of polymeric micellar NPs, via electrophilic aromatic substitution. The choice of the radioisotope ${ }^{64} \mathrm{Cu}$ was justified by its half-life $\left(\mathrm{t}_{1 / 2} \approx 12.7 \mathrm{~h}\right)$, which is compatible with micellar NPs half-life in blood and is thus appropriate to label NPs for monitoring their biodistribution and clearance pathway in vivo. Positon Emission Tomography permits to image the in vivo uptake and clearance profile of ${ }^{64} \mathrm{Cu}$-labeled polymeric micellar NPs in normal $\mathrm{BALB} / \mathrm{c}$ mice, as shown in Figure 13b. Interestingly, the radiolabeled polymer micellar NPs display prolonged blood residence time together with large uptake in EGFR (Epidermal Growth Factor Receptor)-expressing tumor tissue, making them promising candidates for radio-nanomedicine and therapeutic applications.

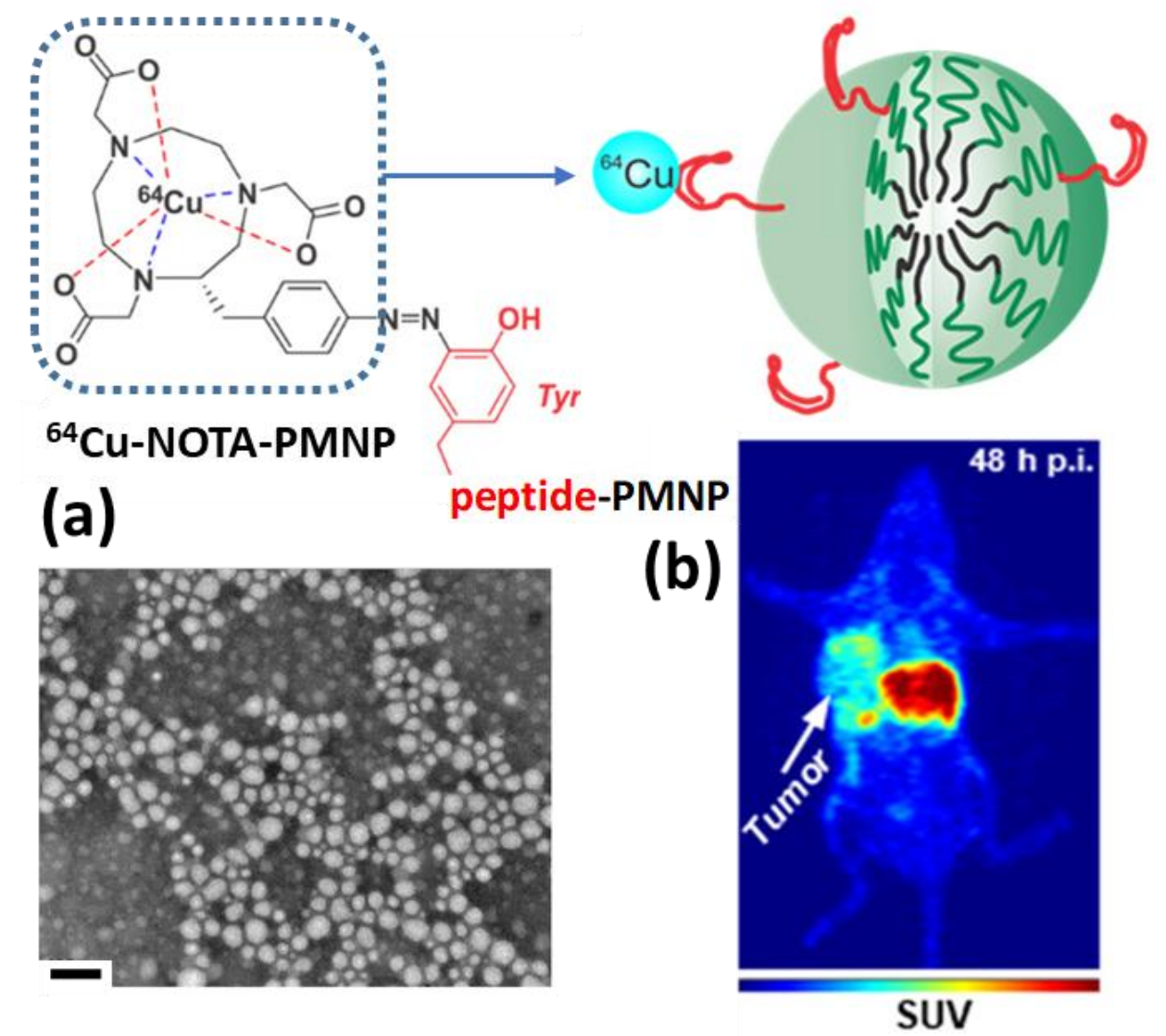

Figure 13. Representative scheme of the structure of radionuclide ${ }^{64} \mathrm{Cu}$-labeled polymeric micellar NPs (top scheme). (a) TEM image of ${ }^{64} \mathrm{Cu}$-labeled polymeric micellar NPs (scale bar $=100 \mathrm{~nm}$ ). (b) PET pictures of normal BALB/c mice at $48 \mathrm{~h}$ after the injection of ${ }^{64} \mathrm{Cu}$-labeled polymeric micellar NPs. Reproduced with permission from ref. 154. Copyright, 2020, American Chemical Society.

Diazonium salt chemistry was also used to design a new generation of SERS encoded-gold nanoparticles for Raman imaging of cells.[151] Simple spherical Au NPs were modified by three different aryl diazonium salts, bearing either nitro or cyano groups and 
carboxyl-terminated functions, using a simple and straightforward process (in air and water, at room temperature). The resulting NPs combined unique SERS signature and post-functionalization ability for the immobilization of the nucleotide adenosine monophosphate. Unlike thiol-derived Raman reporters which tend to form monolayers around $\mathrm{Au}$ NPs, this approach provides strongly anchored multilayers with various chemical groups around the metal NPs, offering new opportunities to obtain multifunctional SERS tags. Proof of concept experiments on different cell lines (EGI-1 and CT-26 cells) showed that these SERS tags could be detected as distinct bright spots after internalization in cells and accumulation into endosomal compartments, opening interesting perspectives for multiplex Raman imaging.

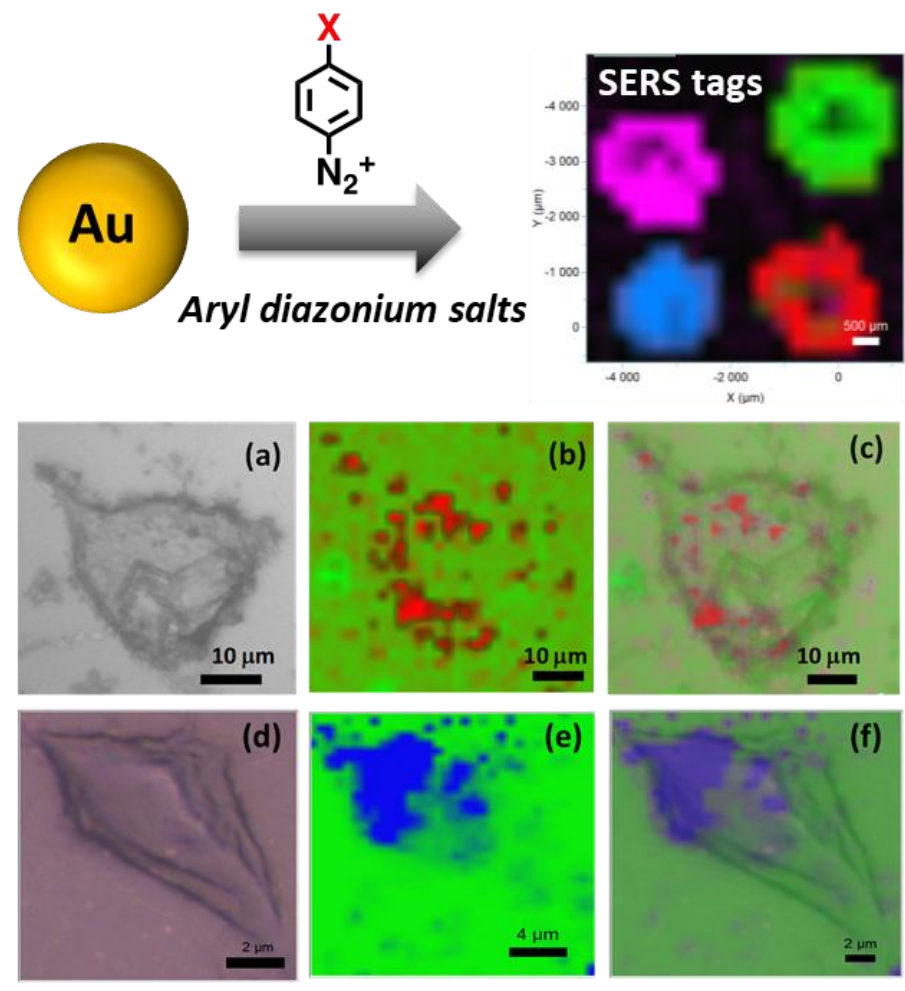

Figure 14. Representative scheme of the design of SERS tags from Au NPs and aryl diazonium salts (top). (a,d) Bright-field optical images and (b,e) Raman images of EGI-1 cells after uptake of SERS tags based on Au NPs modified with multifunctional layers bearing - $\mathrm{CN}$ groups, observed as red spots (b) and CT26 after uptake of SERS tags based on Au NPs modified with multifunctional layers bearing $\mathrm{NO}_{2}$ groups, observed as blue spots (e). (c) Overlay images of (a) and (b); (f) Overlay images of (d) and (e), revealing the intracellular distribution of the SERS tags inside cells. Reproduced with permission from ref. 151. Copyright, 2020, Royal Society of Chemistry.

\section{ANTIBACTERIAL PROPERTIES OF NPS FUNCTIONALIZED BY DIAZONIUM SALTS}

In response to the growing number of antibiotic-resistant bacterial strains, the development of novel antimicrobial materials is attracting growing attention. Towards this end, metal and carbon-based NPs have stimulated interest for their antibacterial activity in houseware, implantable devices, antibiotic delivery systems and medical materials.[155-156] Although the 
antibacterial activity of NPs is not yet fully understood, studies point to the importance of oxidative stress induction, metal ion release, and some non-oxidative mechanisms. Moreover, NPs antimicrobial properties are related to their high surface area, enhancing their interaction with the microorganisms. For most antibacterial applications, surface modification of NPs is necessary in order to improve their colloidal stability and antimicrobial efficiency as well as to decrease their cytotoxicity. In this part, we will discuss the surface functionalization strategies based on aryl diazonium salts developed so far to develop antibacterial metal or carbon-based NPs.

Ag NPs are good candidates for antimicrobial applications due to their ability to release $\mathrm{Ag}^{+}$ions. However, $\mathrm{Ag}$ NPs tend to aggregate in solution, which affects their antibacterial effect. In order to improve their stability in aqueous solution, they were prepared by the simultaneous reduction (by $\mathrm{NaBH}_{4}$ ) of 4-carboxybenzenediazonium and silver nitrate, the carboxylic groups acting as a water-soluble stabilizer (Figure 15a). The resulting nanohybrids displayed robust interfacial Ag-carbon $\sigma$-bonds, which is a key parameter to obtain stable silver NPs. To evaluate their antibacterial properties, a drop of diazonium salt-modified Ag NPs was placed on $S$. Aureus cultured on an agar plate.[157] As shown in Figure 15b-c, the modified Ag NPs induced a distinct inhibition zone after $18 \mathrm{~h}$, demonstrating efficient antibacterial properties towards $S$. Aureus, not observed in the case of control commercially available NPs.
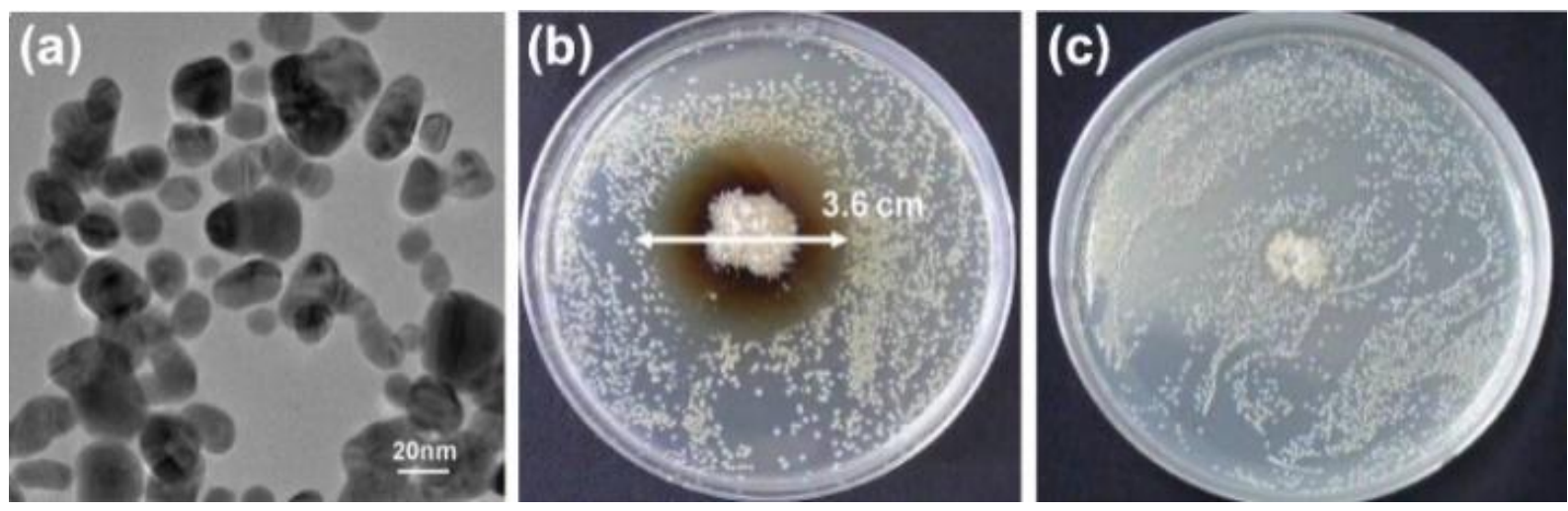

Figure 15. (a) TEM image of Ag NPs modified by aryl diazonium salts, scale bar $=20 \mathrm{~nm}$. Antibacterial effect for (b) modified and (c) control bare Ag NPs after $18 \mathrm{~h}$ incubation with S. Aureus. Reproduced with permission from ref. 157. Copyright, 2012, Elsevier.

Carbon-based nanomaterials were also explored as biocidal source due to their low toxicity to mammalian cells and easy surface functionalization. Up to now, aryl diazonium functionalized CNTs, GO and nanodiamonds have been applied in this field mainly as scaffolds for antibacterial active compounds. For example, MWCNTs were functionalized by lysine, a natural antimicrobial peptide, using diazonium salt chemistry.[158] This covalent functionalization procedure was shown to enhance CNT aqueous solubility, a key parameter for antibacterial applications. Although the morphology analysis by TEM of lysine-grafted CNT revealed some CNT damage due to $\mathrm{sp}^{3}$ carbon hybridization (marked as flash and cage in Figure 16a), this surface functionalization strategy resulted in an improved biocidal activity towards Gram-positive and Gram-negative bacteria compared to pristine CNTs, as shown in Figure 16b. MWCNT were also modified with pyrazole and pyrazolone, yielding 
nanomaterials with an activity against $S$. aureus.[159] When GO or rGO were used as scaffolds, they could load a large amount of cationic poly(L-lysine) antibacterial agents on their surface, thanks to surface-grafted anionic carboxylic acid groups derived from diazonium salts (Figure 16c). The poly(L-lysine)-coated graphene oxide NPs exhibited enhanced antibacterial activity towards $E$. coli with respect to their uncoated counterparts, while being nontoxic and favoring cell attachment and proliferation.[160] Another type of antibacterial nanocomposite could be obtained by using chitosan equipped with an aryldiazonium group to modify graphene sheets. The resulting assembly showed efficient antimicrobial activity, particularly against $S$. dysentiriae,[161] opening the door to a host of new possibilities to fight against microbes.

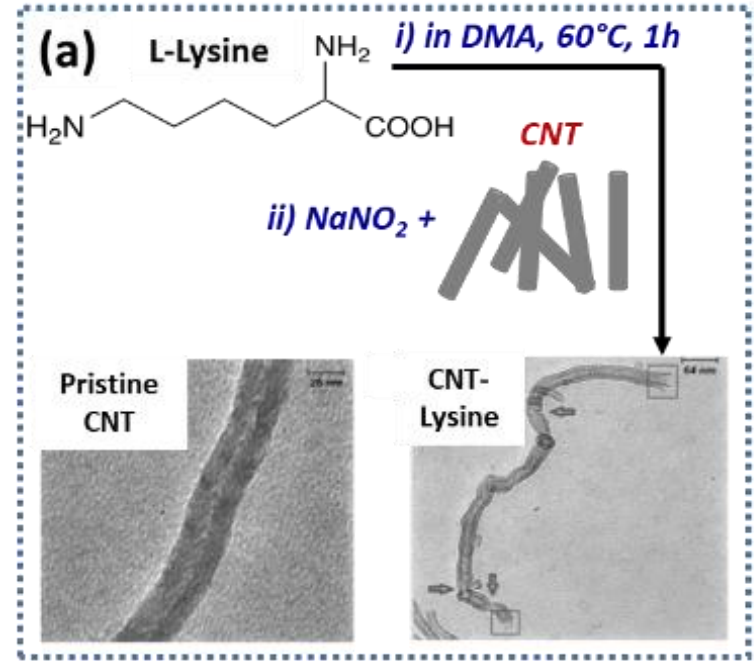

(b)

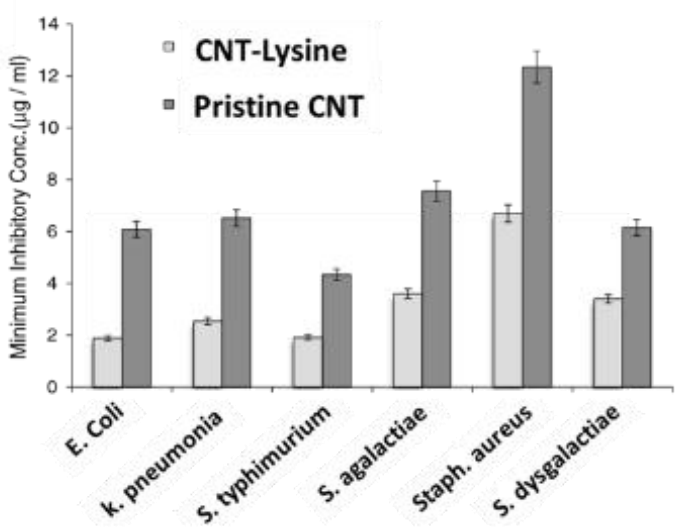

(c)
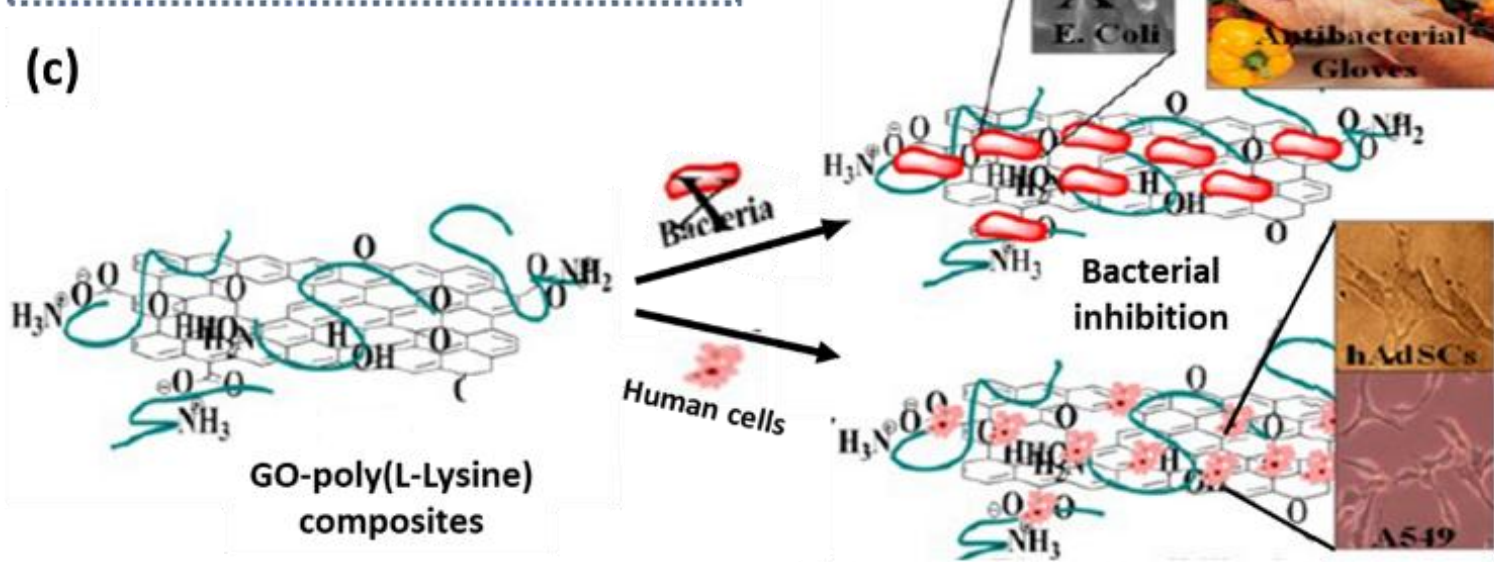

Biocompatibility for human cells growth

Figure 16. (a) Scheme of diazonium-assisted functionalization of CNTs by lysine and TEM images of pristine (scale bar $=25 \mathrm{~nm}$ ) and lysine-coated CNT (scale bar $=64 \mathrm{~nm}$ ). (b) Effect (minimum inhibitory concentration) of pristine and lysine-coated CNT on Gram-negative (E. Coli, S. Typhimurium and K. Pneumonia) and Gram-positive (S. Agalactiae, S. Aureus and S. Dysgalactiae) bacteria. (c) Representative scheme of the surface functionalization of GO and its derivatives by poly(L-lysine), resulting in a dual functionality for the concomitant inhibition of bacterial growth and enhancement of human cell growth. (a), (b) Reproduced and readapted with permission from ref. 158. Copyright, 2012, Elsevier. (c) Reproduced with permission from ref. 160. Copyright, 2012, American Chemical Society. 
Table 1 summarizes the various diazonium salt functionalized nanomaterials described in this review, and their potential applications.

Table 1. Summary of diazonium salt functionalized nanomaterials and their potential applications.

\begin{tabular}{|c|c|c|c|c|}
\hline NPs & $\begin{array}{c}\text { Diazonium salt } \\
\text { functional group }\end{array}$ & Resulting platform & $\begin{array}{c}\text { Targeted } \\
\text { Application }\end{array}$ & $\begin{array}{r}\text { Refer } \\
\text { ence }\end{array}$ \\
\hline \multicolumn{5}{|c|}{ Inorganic nanomaterials } \\
\hline \multicolumn{5}{|c|}{ Metallic NPs } \\
\hline \multirow{5}{*}{$\mathrm{Au}$} & $-\mathrm{COOH}$ & $\mathrm{Au}-\mathrm{BSA}$ & $\begin{array}{c}\text { Intravenous drug } \\
\text { delivery }\end{array}$ & {$[78]$} \\
\hline & $\begin{array}{c}-\mathrm{O}-\mathrm{CH}_{2}-\mathrm{CH}_{2-} \\
\text { DEDTC }\end{array}$ & AuNR@MIPs & $\begin{array}{c}\text { Detection of FA capture } \\
\text { and release }\end{array}$ & [137] \\
\hline & \multirow{2}{*}{$-\mathrm{SH}$} & AuNPs-S-Phe-SPCE & $\begin{array}{c}\text { Determination of } \\
\text { B-type natriuretic } \\
\text { peptide in human serum }\end{array}$ & [146] \\
\hline & & p53-(4-ATP-Np) & $\begin{array}{l}\text { Detection of low } \\
\text { concentration human } \\
\text { p53 proteins }\end{array}$ & [147] \\
\hline & $\begin{array}{c}-\mathrm{NO}_{2},-\mathrm{CN} \\
-\mathrm{COOH}\end{array}$ & $\begin{array}{c}\mathrm{Au} @ \mathrm{CN} @ \mathrm{COOH} \\
@ \mathrm{AMP}, \\
\mathrm{Au} @ \mathrm{NO}_{2} @ \mathrm{COOH} \\
@ \mathrm{AMP}\end{array}$ & $\begin{array}{l}\text { SERS tags used for cell } \\
\text { labeling }\end{array}$ & [151] \\
\hline $\mathrm{Ag}$ & $-\mathrm{COOH}$ & $\begin{array}{c}\text { Diazonium salt modified } \\
\text { Ag NPs }\end{array}$ & $\begin{array}{l}\text { Effective antimicrobial } \\
\text { agent against } S \text {. Aureus }\end{array}$ & [157] \\
\hline \multicolumn{5}{|c|}{ Oxide NPs } \\
\hline Iron oxide & $-\mathrm{COOH}$ & $\begin{array}{l}\text { Hybrid NPs coated with } \\
\text { amphiphilic derivative of } \\
\text { chitosan }\end{array}$ & $\begin{array}{l}\text { Organic-inorganic } \\
\text { hybrid nanocarriers }\end{array}$ & [120] \\
\hline \multicolumn{5}{|c|}{ Carbon-based NPs } \\
\hline Graphene & -NHR & mfG/PEG-FA/ICG/Dox & $\begin{array}{c}\text { Combined cancer } \\
\text { therapy }\end{array}$ & [107] \\
\hline $\begin{array}{l}\text { Reduced } \\
\text { graphene oxide }\end{array}$ & $-\mathrm{COOH}$ & rGO-PEI-FA/DOX & $\begin{array}{c}\mathrm{pH} \text { - and salt-dependent } \\
\text { drug release }\end{array}$ & [108] \\
\hline Q-Graphene & $-\mathrm{COOH}$ & HA-Q-G-RBITC/DOX & $\begin{array}{l}\text { Tracking and monitoring } \\
\text { targeted drug delivery }\end{array}$ & [109] \\
\hline $\begin{array}{c}\text { Fluorescent } \\
\text { nanodiamonds }\end{array}$ & $-\mathrm{CH}\left(\mathrm{CH}_{3}\right)-\mathrm{Br}$ & Hairy fND-PtBMA & Protein carrier & [112] \\
\hline Nanodiamonds & $-\mathrm{COOH},-\mathrm{NH}_{2}$ & Amphiphilic nanohybrids & Biomolecule carrier & [113] \\
\hline $\mathrm{rGO}, \mathrm{Au}$ NPs & $\begin{array}{l}-\mathrm{NO}_{2},-\mathrm{NH}_{2} \\
-\mathrm{COOH}\end{array}$ & rGO-ph-AuNP & $\begin{array}{l}\text { Label-free detection of } \\
\text { TNF- } \alpha\end{array}$ & [144] \\
\hline $\begin{array}{l}\text { Single-walled } \\
\text { carbon } \\
\text { nanotubes }\end{array}$ & $-\mathrm{NH}_{2}$ & $\begin{array}{c}\text { Vertically aligned } \\
\text { single-walled carbon } \\
\text { nanotubes (VASWCNTs) }\end{array}$ & $\begin{array}{l}\text { Electrochemical } \\
\text { investigation of } \\
\text { intracellular } \\
\text { environment }\end{array}$ & [148] \\
\hline
\end{tabular}




\begin{tabular}{|c|c|c|c|c|}
\hline $\begin{array}{c}\text { Carbon } \\
\text { nano-onions }\end{array}$ & $\begin{array}{l}-\mathrm{COOH} \\
-\mathrm{C} \equiv \mathrm{CH}\end{array}$ & $\begin{array}{c}\text { Multi- Functionalized } \\
\text { CNOs }\end{array}$ & $\begin{array}{l}\text { Imaging probes for the } \\
\text { detection of cancer cells }\end{array}$ & [152] \\
\hline $\begin{array}{l}\text { Multi-walled } \\
\text { carbon } \\
\text { nanotubes }\end{array}$ & Lysine & $\begin{array}{l}\text { Lysine functionalized } \\
\text { MWCNT }\end{array}$ & $\begin{array}{c}\text { Improved biocidal } \\
\text { property towards } \\
\text { Gram-positive and } \\
\text { Gram-negative bacteria }\end{array}$ & [158] \\
\hline Graphene oxide & $-\mathrm{COOH}$ & $\begin{array}{l}\text { GO-poly(L-lysine }) \\
\text { composites }\end{array}$ & $\begin{array}{c}\text { Antibacterial agent } \\
\text { against } E \text {. coli }\end{array}$ & [160] \\
\hline \multicolumn{5}{|c|}{ Other type of inorganic NPs } \\
\hline $\begin{array}{c}\text { Black } \\
\text { phosphorous } \\
\text { nanosheets }\end{array}$ & Nile blue & NB@BPs & $\begin{array}{c}\text { Near-infrared } \\
\text { imaging-guided } \\
\text { photothermal therapy }\end{array}$ & [153] \\
\hline \multicolumn{5}{|c|}{ Organic NPs } \\
\hline Viral capsids & $-\mathrm{NO}_{2}$ & $\begin{array}{c}\text { Dual functionalized MS2 } \\
\text { capsids }\end{array}$ & $\begin{array}{c}\text { Therapeutic cargo } \\
\text { delivery }\end{array}$ & [125] \\
\hline $\begin{array}{c}\text { Polymeric } \\
\text { micellar NPs } \\
\text { (PMNPs), }{ }^{64} \mathrm{Cu}\end{array}$ & $\begin{array}{l}\text {-NOTA-Bn- } \\
\quad \mathrm{NH}_{2}\end{array}$ & $\begin{array}{c}{ }^{64} \mathrm{Cu}-\mathrm{NOTA}-\mathrm{GE} 11- \\
\text { PMNPs }\end{array}$ & $\begin{array}{c}\text { EGFR-targeted } \\
\text { molecular positron } \\
\text { emission tomography } \\
\text { imaging }\end{array}$ & [154] \\
\hline
\end{tabular}

\section{CONCLUSIONS}

This review presents a number of examples of nanoparticle functionalization by diazonium salts for biomedical sciences. Metal and organic nanoparticles can be prepared and functionalized quite easily and their small size permits their penetration in various biological media, where they can transport drugs, imaging agents, sensing groups or antibacterial coatings. The main interest of diazonium based coatings relies on the stability of the bond between the NPs and the grafted organic layers that prevents the fast release of the coating under biological conditions. The grafted polyaryl layers are more stable than physisorbed molecules or thiols on metals, and they do not hydrolyze as silane-modified surfaces. Moreover, surface functionalization with aryl diazonium salts can be performed on a wide variety of materials, including oxides, metals, carbon-based NPs and viruses. Note that this review includes two different chemistries of diazonium salts: aryl radical chemistry and electrophilic substitution, both leading to strong bonding of the coating on the NPs. The second interest relies on the flexible chemistry provided by the substitution of the aryl group that permits to graft a large choice of (bio-)molecules modified at a given position or simple aryl groups to provide platforms for further post-functionalization.

However, the examples of this review are limited to proofs of concepts and this growing field is still in its infancy regarding practical and real world biomedical applications. There is now approximatively a hundred of NPs pharmaceutical formulations on the market, based on inorganic NPs, liposomes, pegylated proteins and polymers [162] Nevertheless, only few examples are based on NPs modified by diazonium salts. One can cite supermagnetic iron oxide NPs (SPIO) modified with $\mathrm{NH}_{2}, \mathrm{COOH}$ or $\mathrm{N}_{3}$ groups using diazonium salt chemistry, such as Turbobeads ${ }^{\circledR}[$ https://www.turbobeads.com]. 
Generally, there remain several challenges to address before surface functionalization methods based on diazonium salts achieve their full potential for biomedecine. From a theoretical perspective, much remains to be known about the mechanisms of surface grafting on various NPs types and the critical role of the interface. From a practical standpoint, the design of nanohybrids with long-term stability in biological environments and under various external stimulations (light, temperature, $\mathrm{pH}$...) should be given attention. In addition, the possibility to precisely control the chemical nature and structure of the polyaryl layers grafted around the NPs constitutes another promising research direction. Indeed, these polyaryl layers may bring solutions to the payload problem, as the grafted oligomers can carry a larger number of drugs than monolayers (as for example with silanes on $\mathrm{SiO}_{2}$ ). For example, carbon and gold surfaces were modified recently by a diazonium salt that can release pyrene as a drug mimic. Upon electrochemical reduction, all the pyrene groups attached to the oligoaryl layers could be released $\left(1.510^{-9}\right.$ mole $\left.\mathrm{cm}^{-2}\right)$ [163] Finally, efforts are still required to obtain new insights on the toxicological properties of the NPs functionalized by diazonium salts and to further improve their biosafety. To meet all these challenges and strengthen the place of diazonium salt chemistry for surface functionalization of NPs in biomedicine, collaborative and translational investigations will be necessary to cover both chemical, pharmaceutical, toxicological and medical aspects.

\section{CORRESPONDING AUTHORS}

*E-mail: claire.mangeney@u-paris.fr

*E-mail: jean.pinson@univ-paris-diderot.fr

*E-mail: yun.luo@u-paris.fr

\section{DECLARATION OF COMPETING INTERESTS}

The authors declare that they have no known competing financial interests or personal relationships that could have appeared to influence the work reported in this paper.

\section{ACKNOWLEDGMENT}

This work was partly supported by the IdEx Université de Paris, ANR-18-IDEX-0001 and the scholarship from China Scholarship Council (CSC) under the Grant CSC $\mathrm{N}^{\circ}$ 201909370060.

\section{REFERENCES}

[1] Daniel MC, Astruc D. Gold nanoparticles: assembly, supramolecular chemistry, quantum-size-related properties, and applications toward biology, catalysis, and nanotechnology. Chem Rev 2004;104:293-346.

[2] Kelly KL, Coronado E, Zhao LL, Schatz GC. The optical properties of metal nanoparticles: the influence of size, shape, and dielectric environment. ACS Publications; 2003.

[3] Laurent S, Forge D, Port M, Roch A, Robic C, Vander Elst L, et al. Magnetic iron oxide nanoparticles: synthesis, stabilization, vectorization, physicochemical characterizations, and biological applications. Chem Rev 2008;108:2064-110.

[4] Trindade T, O'Brien P, Pickett NL. Nanocrystalline semiconductors: synthesis, properties, and perspectives. Chem Mater 2001;13:3843-58. 
[5] Nagavarma B, Yadav HK, Ayaz A, Vasudha L, Shivakumar H. Different techniques for preparation of polymeric nanoparticles-a review. Asian J Pharm Clin Res 2012;5:16-23.

[6] Kesharwani P, Jain K, Jain NK. Dendrimer as nanocarrier for drug delivery. Prog Polym Sci 2014;39:268-307.

[7] Hawkins MJ, Soon-Shiong P, Desai N. Protein nanoparticles as drug carriers in clinical medicine. Adv Drug Deliv Rev 2008;60:876-85.

[8] Müller RH, Mäder K, Gohla S. Solid lipid nanoparticles (SLN) for controlled drug delivery-a review of the state of the art. Eur J Pharm Biopharm 2000;50:161-77.

[9] Thanh NT, Green LA. Functionalisation of nanoparticles for biomedical applications. Nano Today 2010;5:213-30.

[10] Shi J, Kantoff PW, Wooster R, Farokhzad OC. Cancer nanomedicine: progress, challenges and opportunities. Nat Rev Cancer 2017;17:20.

[11] Howes PD, Chandrawati R, Stevens MM. Colloidal nanoparticles as advanced biological sensors. Science 2014;346.

[12] Lee D-E, Koo H, Sun I-C, Ryu JH, Kim K, Kwon IC. Multifunctional nanoparticles for multimodal imaging and theragnosis. Chem Soc Rev 2012;41:2656-72.

[13] Wang L, Hu C, Shao L. The antimicrobial activity of nanoparticles: present situation and prospects for the future. Int J Nanomed 2017;12:1227.

[14] Sahay G, Alakhova DY, Kabanov AV. Endocytosis of nanomedicines. J Control Release 2010;145:182-95.

[15] Ragelle H, Danhier F, Préat V, Langer R, Anderson DG. Nanoparticle-based drug delivery systems: a commercial and regulatory outlook as the field matures. Expert Opin Drug Deliv 2017;14:851-64.

[16] Rani K, Paliwal S. A review on targeted drug delivery: Its entire focus on advanced therapeutics and diagnostics. Sch J App Med Sci 2014;2:328-31.

[17] Iwamoto T. Clinical application of drug delivery systems in cancer chemotherapy: review of the efficacy and side effects of approved drugs. Biol Pharm Bull 2013;36:715-718.

[18] Lee K-S, El-Sayed MA. Gold and silver nanoparticles in sensing and imaging: sensitivity of plasmon response to size, shape, and metal composition. $\mathrm{J}$ Phys Chem $\mathrm{B}$ 2006;110:19220-19225.

[19] Sun S, Zeng H, Robinson DB, Raoux S, Rice PM, Wang SX, et al. Monodisperse mfe2o4 $(\mathrm{m}=\mathrm{fe}, \mathrm{co}, \mathrm{mn})$ nanoparticles. J Am Chem Soc 2004;126:273-9.

[20] Li Z, Barnes JC, Bosoy A, Stoddart JF, Zink JI. Mesoporous silica nanoparticles in biomedical applications. Chem Soc Rev 2012;41:2590-605.

[21] Mout R, Moyano DF, Rana S, Rotello VM. Surface functionalization of nanoparticles for nanomedicine. Chem Soc Rev 2012;41:2539-44.

[22] Lynch I, Dawson KA. Protein-nanoparticle interactions. Nano Today 2008;3:40-7.

[23] Neouze M-A, Schubert U. Surface modification and functionalization of metal and metal oxide nanoparticles by organic ligands. Monatsh Chem 2008;139:183-95.

[24] De Palma R, Peeters S, Van Bael MJ, Van den Rul H, Bonroy K, Laureyn W, et al. Silane ligand exchange to make hydrophobic superparamagnetic nanoparticles water-dispersible. Chem Mater 2007;19:1821-31.

[25] Park J-W, Shumaker-Parry JS. Structural study of citrate layers on gold nanoparticles: role of intermolecular interactions in stabilizing nanoparticles. J Am Chem Soc 2014;136:1907-21. 
[26] Yee C, Kataby G, Ulman A, Prozorov T, White H, King A, et al. Self-assembled monolayers of alkanesulfonic and-phosphonic acids on amorphous iron oxide nanoparticles. Langmuir 1999; 15:7111-5.

[27] Liao H, Hafner JH. Gold nanorod bioconjugates. Chem Mater 2005;17:4636-41.

[28] Baquero EA, Tricard S, Flores JC, de Jesús E, Chaudret B. Highly Stable Water- Soluble Platinum Nanoparticles Stabilized by Hydrophilic N- Heterocyclic Carbenes. Angew Chem 2014;126:13436-40.

[29] Berisha A, Chehimi MM, Pinson J, Podvorica F. Electrode surface modification using diazonium salts. Electroanal Chem 2015:115-224.

[30] Chehimi MM. Aryl diazonium salts: new coupling agents in polymer and surface science: John Wiley \& Sons; 2012.

[31] Mahouche-Chergui S, Gam-Derouich S, Mangeney C, Chehimi MM. Aryl diazonium salts: a new class of coupling agents for bonding polymers, biomacromolecules and nanoparticles to surfaces. Chem Soc Rev 2011;40:4143-66.

[32] Laurentius L, Stoyanov SR, Gusarov S, Kovalenko A, Du R, Lopinski GP, et al. Diazonium-derived aryl films on gold nanoparticles: Evidence for a carbon-gold covalent bond. ACS Nano 2011;5:4219-27.

[33] Mesnage A, Esnouf S, Jégou P, Deniau G, Palacin S. Understanding the redox-induced polymer grafting process: A dual surface-solution analysis. Chem Mater 2010;22:6229-39.

[34] Xia Y, Martin C, Seibel J, Eyley S, Thielemans W, van der Auweraer M, et al. Iodide mediated reductive decomposition of diazonium salts: towards mild and efficient covalent functionalization of surface-supported graphene. Nanoscale 2020;12:11916-26.

[35] Allongue P, Delamar M, Desbat B, Fagebaume O, Hitmi R, Pinson J, et al. Covalent modification of carbon surfaces by aryl radicals generated from the electrochemical reduction of diazonium salts. J Am Chem Soc 1997;119:201-7.

[36] Leroux YR, Hui F, Noël J-M, Roux C, Downard AJ, Hapiot P. Design of robust binary film onto carbon surface using diazonium electrochemistry. Langmuir 2011;27:11222-8.

[37] Bouriga M, Chehimi MM, Combellas C, Decorse P, Kanoufi F, Deronzier A, et al. Sensitized Photografting of Diazonium Salts by Visible Light. Chem Mater 2013;25:90-7.

[38] Tijunelyte I, Kherbouche I, Gam-Derouich S, Nguyen M, Lidgi-Guigui N, de la Chapelle ML, et al. Multi-functionalization of lithographically designed gold nanodisks by plasmon-mediated reduction of aryl diazonium salts. Nanoscale Horiz 2018;3:53-7.

[39] Fernandez-Bravo A, Sivakumar P, Melikechi N, Mohamed AA. Femtosecond laser ablation synthesis of aryl functional group substituted gold nanoparticles. J Nanosci Nanotechnol 2017;17:2852-6.

[40] Gooding JJ, Ciampi S. The molecular level modification of surfaces: from self-assembled monolayers to complex molecular assemblies. Chem Soc Rev 2011;40:2704-18.

[41] Howard A, Wild F. The reactions of diazonium compounds with amino acids and proteins. Biochem J 1957;65:651.

[42] Hetemi D, Noël V, Pinson J. Grafting of diazonium salts on surfaces: application to biosensors. Biosensors 2020;10:4.

[43] Troian-Gautier L, Mattiuzzi A, Reinaud O, Lagrost C, Jabin I. Use of calixarenes bearing diazonium groups for the development of robust monolayers with unique tailored properties. Org Biomol Chem 2020;18:3624-37. 
[44] Kochi JK. The mechanism of the Sandmeyer and Meerwein reactions. J Am Chem Soc 1957;79:2942-8.

[45] Rondestvedt Jr CS. Arylation of Unsaturated Compounds by Diazonium Salts (The M eerwein Arylation Reaction). Org React 2004;11:189-260.

[46] Pratsch G, Heinrich M, Heinrich M. Radicals in Synthesis III. Top Curr Chem 2012;320.

[47] Berisha A, Combellas C, Kanoufi Fdr, Decorse P, Oturan N, Médard Jrm, et al. Some theoretical and experimental insights on the mechanistic routes leading to the spontaneous grafting of gold surfaces by diazonium salts. Langmuir 2017;33:8730-8.

[48] Sheng M, Frurip D, Gorman D. Reactive chemical hazards of diazonium salts. J Loss Prev Process Ind 2015;38:114-8.

[49] Tang Y, Imler GH, Parrish DA, Shreeve JnM. C6N10O4: Thermally Stable Nitrogen-Rich Inner Bis (diazonium) Zwitterions. Org Lett 2019;21:8201-4.

[50] Bondarev AA, Naumov EV, Kassanova AZ, Krasnokutskaya EA, Stankevich KS, Filimonov VD. First study of the thermal and storage stability of arenediazonium triflates comparing to 4-nitrobenzenediazonium tosylate and tetrafluoroborate by calorimetric methods. Org Process Res Dev 2019;23:2405-15.

[51] Pazo- Llorente R, Bravo- Diaz C, Gonzalez- Romero E. pH effects on ethanolysis of some arenediazonium ions: evidence for homolytic dediazoniation proceeding through formation of transient diazo ethers. Eur J Org Chem 2004;2004:3221-6.

[52] Pazo- Llorente R, Maskill H, Bravo- Diaz C, Gonzalez- Romero E. Dediazoniation of 4- Nitrobenzenediazonium Ions in Acidic $\mathrm{MeOH} / \mathrm{H} 2 \mathrm{O}$ Mixtures: Role of Acidity and $\mathrm{MeOH}$ Concentration on the Formation of Transient Diazo Ethers that Initiate Homolytic Dediazoniation. Wiley Online Library; 2006.

[53] Rappoport Z, Liebman JF. The Chemistry of Hydroxylamines, Oximes and Hydroxamic Acids, Volume 1: John Wiley \& Sons; 2008.

[54] Chen B, Flatt AK, Jian H, Hudson JL, Tour JM. Molecular grafting to silicon surfaces in air using organic triazenes as stable diazonium sources and $\mathrm{HF}$ as a constant hydride-passivation source. Chem Mater 2005;17:4832-6.

[55] Pinson J, Podvorica F. Attachment of organic layers to conductive or semiconductive surfaces by reduction of diazonium salts. Chem Soc Rev 2005;34:429-39.

[56] Kornblum N, Cooper GD, Taylor JE. The Chemistry of Diazo Compounds. II. Evidence for a Free Radical Chain Mechanism in the Reduction of Diazonium Salts by Hypophosphorous Acid1, 2. J Am Chem Soc 1950;72:3013-21.

[57] Heald CG, Wildgoose GG, Jiang L, Jones TG, Compton RG. Chemical derivatisation of multiwalled carbon nanotubes using diazonium salts. ChemPhysChem 2004;5:1794-9.

[58] Chaussé A, Chehimi MM, Karsi N, Pinson J, Podvorica F, Vautrin-Ul C. The electrochemical reduction of diazonium salts on iron electrodes. The formation of covalently bonded organic layers and their effect on corrosion. Chem Mater 2002;14:392-400.

[59] Adenier A, Combellas C, Kanoufi F, Pinson J, Podvorica FI. Formation of polyphenylene films on metal electrodes by electrochemical reduction of benzenediazonium salts. Chem Mater 2006;18:2021-9.

[60] Mahouche-Chergui S, Guerrouache M, Carbonnier B, Chehimi MM. Polymer-immobilized nanoparticles. Colloids Surf A Physicochem Eng Asp 2013;439:43-68.

[61] Chehimi MM, Pinson J, Salmi Z. Carbon nanotubes: surface modification and 
applications. Appl Surf Sci 2013:95-143.

[62] Doppelt P, Hallais G, Pinson J, Podvorica F, Verneyre S. Surface modification of conducting substrates. Existence of azo bonds in the structure of organic layers obtained from diazonium salts. Chem Mater 2007;19:4570-5.

[63] Sanders S, Golden TD. Functionalization of Cerium Oxide Nanoparticles to Influence Hydrophobic Properties. Langmuir 2019;35:5841-7.

[64] Kuila A, Maity N, Layek RK, Nandi AK. On the pH sensitive optoelectronic properties of amphiphilic reduced graphene oxide via grafting of poly (dimethylaminoethyl methacrylate): a signature of p-and n-type doping. J Mater Chem A 2014;2:16039-50.

[65] Van Gorp H, Walke P, Teyssandier J, Hirsch BE, Uji-i H, Tahara K, et al. On the Thermal Stability of Aryl Groups Chemisorbed on Graphite. J Phys Chem C 2019;124:1980-90.

[66] Schirowski M, Hauke F, Hirsch A. Controlling the Degree of Functionalization: In- Depth Quantification and Side- Product Analysis of Diazonium Chemistry on SWCNTs. Chemistry (Weinheim an der Bergstrasse, Germany). 2019;25:12761.

[67] Atmane YA, Sicard L, Lamouri A, Pinson J, Sicard Ml, Masson C, et al. Functionalization of aluminum nanoparticles using a combination of aryl diazonium salt chemistry and iniferter method. J Phys Chem C 2013;117:26000-6.

[68] Unwin PR, Güell AG, Zhang G. Nanoscale electrochemistry of sp2 carbon materials: from graphite and graphene to carbon nanotubes. Acc Chem Res 2016;49:2041-8.

[69] Bahr JL, Tour JM. Highly functionalized carbon nanotubes using in situ generated diazonium compounds. Chem Mater 2001;13:3823-4.

[70] Majeed W, Bourdo S, Petibone DM, Saini V, Vang KB, Nima ZA, et al. The role of surface chemistry in the cytotoxicity profile of graphene. J Appl Toxicol 2017;37:462-470.

[71] Shen H, Zhang L, Liu M, Zhang Z. Biomedical applications of graphene. Theranostics. 2012;2:283.

[72] Gao W. The chemistry of graphene oxide. Graphene oxide. 2015:61-95.

[73] Tkachev S, Buslaeva EY, Naumkin A, Kotova S, Laure I, Gubin S. Reduced graphene oxide. Inorg Mater 2012;48:796-802.

[74] Yang K, Feng L, Shi X, Liu Z. Nano-graphene in biomedicine: theranostic applications. Chem Soc Rev 2013;42:530-47.

[75] Kimling J, Maier M, Okenve B, Kotaidis V, Ballot H, Plech A. Turkevich method for gold nanoparticle synthesis revisited. J Phys Chem B 2006;110:15700-7.

[76] Martin MN, Basham JI, Chando P, Eah S-K. Charged gold nanoparticles in non-polar solvents: 10-min synthesis and 2D self-assembly. Langmuir 2010;26:7410-7.

[77] Ahmad AA, Workie B, Mohamed AA. Diazonium Gold Salts as Novel Surface Modifiers: What Have We Learned So Far? Surfaces 2020;3:182-96.

[78] Hameed MK, Ahmady IM, Alawadhi H, Workie B, Sahle-Demessie E, Han C, et al. Gold-carbon nanoparticles mediated delivery of BSA: Remarkable robustness and hemocompatibility. Colloids Surf A Physicochem Eng Asp 2018;558:351-8.

[79] Nguyen V-Q, Ai Y, Martin P, Lacroix J-C. Plasmon-induced nanolocalized reduction of diazonium salts. ACS Omega 2017;2:1947-55.

[80] Miliutina E, Guselnikova O, Bainova P, Kalachyova Y, Elashnikov R, Yusubov MS, et al. Plasmon- Assisted Activation and Grafting by Iodonium Salt: Functionalization of Optical Fiber Surface. Adv Mater Interfaces 2018;5:1800725. 
[81] Nguyen M, Kherbouche I, Gam-Derouich S, Ragheb I, Lau-Truong S, Lamouri A, et al. Regioselective surface functionalization of lithographically designed gold nanorods by plasmon-mediated reduction of aryl diazonium salts. Chem Commun 2017;53:11364-7.

[82] Miliutina E, Guselnikova O, Chufistova S, Kolska Z, Elashnikov R, Burtsev V, et al. Fast and all-optical hydrogen sensor based on gold-coated optical fiber functionalized with metal-organic framework layer. ACS Sensors. 2019;4:3133-40.

[83] Nguyen M, Felidj N, Mangeney C. Looking for synergies in molecular plasmonics through hybrid thermoresponsive nanostructures. Chem Mater 2016;28:3564-77.

[84] Vilà N, Van Brussel M, D’Amours M, Marwan J, Buess-Herman C, Bélanger D. Metallic and bimetallic $\mathrm{Cu} / \mathrm{Pt}$ species supported on carbon surfaces by means of substituted phenyl groups. J Electroanal Chem 2007;609:85-93.

[85] Noël J-M, Zigah D, Simonet J, Hapiot P. Synthesis and immobilization of Ag0 nanoparticles on diazonium modified electrodes: SECM and cyclic voltammetry studies of the modified interfaces. Langmuir 2010;26:7638-43.

[86] Zhou Z-Y, Kang X, Song Y, Chen S. Ligand-mediated electrocatalytic activity of Pt nanoparticles for oxygen reduction reactions. J Phys Chem C 2012;116:10592-8.

[87] Yang S, Li G, Zhu Q, Pan Q. Covalent binding of Si nanoparticles to graphene sheets and its influence on lithium storage properties of $\mathrm{Si}$ negative electrode. J Mater Chem 2012;22:3420-5.

[88] Zhang L, Gao LF, Li L, Hu C-X, Yang Q-Q, Zhu Z-Y, et al. Negatively charged 2D black phosphorus for highly efficient covalent functionalization. Mater Chem Front 2018;2:1700-6. [89] Mitrović A, Wild S, Lloret V, Fickert M, Assebban M, Márkus B, et al. Interface amorphization of two- dimensional black phosphorus upon the treatment with diazonium salts. Chem Eur J 2021;27:3361-3366.

[90] Ryder CR, Wood JD, Wells SA, Yang Y, Jariwala D, Marks TJ, et al. Covalent functionalization and passivation of exfoliated black phosphorus via aryl diazonium chemistry. Nat Chem 2016;8:597-602.

[91] Bunge A, Magerusan L, Morjan I, Turcu R, Borodi G, Liebscher J. Diazonium salt-mediated synthesis of new amino, hydroxy, propargyl, and maleinimido-containing superparamagnetic Fe@ C nanoparticles as platforms for linking bio-entities or organocatalytic moieties. J Nanopart Res 2015;17:1-16.

[92] Gupta G, Iqbal P, Yin F, Liu J, Palmer R, Sharma S, et al. Pt diffusion dynamics for the formation Cr-Pt core-shell nanoparticles. Langmuir 2015;31:6917-23.

[93] Zhang S, Gao H, Bao G. Physical principles of nanoparticle cellular endocytosis. ACS Nano 2015;9:8655-71.

[94] Cai R, Chen C. The crown and the scepter: roles of the protein corona in nanomedicine. Adv Mater 2019;31:1805740.

[95] Muraca F, Boselli L, Castagnola V, Dawson KA. Ultrasmall Gold Nanoparticle Cellular Uptake: Influence of Transient Bionano Interactions. ACS Appl Bio Mater 2020;3:3800-8.

[96] Feliu N, Docter D, Heine M, Del Pino P, Ashraf S, Kolosnjaj-Tabi J, et al. In vivo degeneration and the fate of inorganic nanoparticles. Chem Soc Rev 2016;45:2440-57.

[97] Kolosnjaj-Tabi J, Javed Y, Lartigue L, Volatron J, Elgrabli D, Marangon I, et al. The one year fate of iron oxide coated gold nanoparticles in mice. ACS Nano 2015;9:7925-39.

[98] Volatron J, Carn F, Kolosnjaj- Tabi J, Javed Y, Vuong QL, Gossuin Y, et al. Ferritin 
protein regulates the degradation of iron oxide nanoparticles. Small 2017;13:1602030.

[99] Martín C, Kostarelos K, Prato M, Bianco A. Biocompatibility and biodegradability of 2D materials: graphene and beyond. Chem Commun 2019;55:5540-6.

[100] Balfourier A, Luciani N, Wang G, Lelong G, Ersen O, Khelfa A, et al. Unexpected intracellular biodegradation and recrystallization of gold nanoparticles. Proc Nat Acad Sci 2020;117:103-13.

[101] Ahmed A, Sarwar S, Hu Y, Munir MU, Nisar MF, Ikram F, et al. Surface-modified polymeric nanoparticles for drug delivery to cancer cells. Expert Opin Drug Deliv 2021;18:1-24.

[102] Gupta AK, Gupta M. Synthesis and surface engineering of iron oxide nanoparticles for biomedical applications. Biomaterials 2005;26:3995-4021.

[103] De Jong WH, Borm PJ. Drug delivery and nanoparticles: applications and hazards. Int J Nanomed 2008;3:133.

[104] Petros RA, DeSimone JM. Strategies in the design of nanoparticles for therapeutic applications. Nat Rev Drug Discov 2010;9:615-27.

[105] Anselmo A, Mitragotri S. Nanoparticles in the clinic. Bioeng Transl Med 2016; 1: 10-29. [106] Liu J, Cui L, Kong N, Barrow CJ, Yang W. RAFT controlled synthesis of graphene/polymer hydrogel with enhanced mechanical property for $\mathrm{pH}$-controlled drug release. Eur Polym J 2014;50:9-17.

[107] Lucherelli MA, Yu Y, Reina G, Abellán G, Miyako E, Bianco A. Rational chemical multifunctionalization of graphene interface enhances targeted cancer therapy. Angew Chem 2020; 59:14034-14039.

[108] Wei G, Yan M, Dong R, Wang D, Zhou X, Chen J, et al. Covalent modification of reduced graphene oxide by means of diazonium chemistry and use as a drug- delivery system. Chem Eur J 2012;18:14708-16.

[109] Luo Y, Cai X, Li H, Lin Y, Du D. Hyaluronic acid-modified multifunctional Q-graphene for targeted killing of drug-resistant lung cancer cells. ACS Appl Mater Interfaces 2016;8:4048-55.

[110] Chauhan S, Jain N, Nagaich U. Nanodiamonds with powerful ability for drug delivery and biomedical applications: Recent updates on in vivo study and patents. J Pharm Biomed Anal 2020;10:1-12.

[111] Turcheniuk K, Mochalin V N. Biomedical applications of nanodiamond. Nanotechnology 2017;28:252001.

[112] Dahoumane SA, Nguyen MN, Thorel A, Boudou JP, Chehimi MM, Mangeney C. Protein-functionalized hairy diamond nanoparticles. Langmuir 2009;25:9633-9638.

[113] Fraczyk J, Rosowski A, Kolesinska B, Koperkiewcz A, Guzenda AS, Kaminski ZJ, et al. Orthogonal functionalization of nanodiamond particles after laser modification and treatment with aromatic amine derivatives. Nanomaterials 2018;8:908.

[114] Tietze R, Zaloga J, Unterweger H, Lyer S, Friedrich RP, Janko C, et al. Magnetic nanoparticle-based drug delivery for cancer therapy. Biochem Biophys Res Commun 2015;468:463-70.

[115] Su S, Zuo X, Pan D, Pei H, Wang L, Fan C, et al. Design and applications of gold nanoparticle conjugates by exploiting biomolecule-gold nanoparticle interactions. Nanoscale 2013;5:2589-99. 
[116] Zhu N, Ji H, Yu P, Niu J, Frooq MU, Akram MW, et al. Surface modification of magnetic iron oxide nanoparticles. Nanomaterials 2018;8:810.

[117] Dilnawaz F, Singh A, Mohanty C, Sahoo SK. Dual drug loaded superparamagnetic iron oxide nanoparticles for targeted cancer therapy. Biomaterials 2010;31:3694-706.

[118] Lee N, Yoo D, Ling D, Cho MH, Hyeon T, Cheon J. Iron Oxide Based Nanoparticles for Multimodal Imaging and Magnetoresponsive Therapy. Chem Rev 2015;115:10637-10689.

[119] Chertok B, Moffat BA, David AE, Yu F, Bergemann C, Ross BD, et al. Iron oxide nanoparticles as a drug delivery vehicle for MRI monitored magnetic targeting of brain tumors. Biomaterials 2008;29:487-96.

[120] Di Martino A, Guselnikova OA, Trusova ME, Postnikov PS, Sedlarik V. Organic-inorganic hybrid nanoparticles controlled delivery system for anticancer drugs. Int J Pharm 2017;526:380-90.

[121] Ahmad R, Griffete N, Lamouri A, Mangeney C. Functionalization of magnetic nanocrystals by oligo (ethylene oxide) chains carrying diazonium and iniferter end groups. J Colloid Interface Sci 2013;407:210-4.

[122] Schoonen L, van Hest JC. Functionalization of protein-based nanocages for drug delivery applications. Nanoscale 2014;6:7124-41.

[123] Bruckman MA, Czapar AE, VanMeter A, Randolph LN, Steinmetz NF. Tobacco mosaic virus-based protein nanoparticles and nanorods for chemotherapy delivery targeting breast cancer. J Control Release 2016;231:103-13.

[124] Bruckman MA, Randolph LN, VanMeter A, Hern S, Shoffstall AJ, Taurog RE, et al. Biodistribution, pharmacokinetics, and blood compatibility of native and PEGylated tobacco mosaic virus nano-rods and-spheres in mice. Virology 2014;449:163-73.

[125] Kovacs EW, Hooker JM, Romanini DW, Holder PG, Berry KE, Francis MB. Dual-surface-modified bacteriophage MS2 as an ideal scaffold for a viral capsid-based drug delivery system. Bioconjug Chem 2007;18:1140-7.

[126] Bruckman MA, Kaur G, Lee LA, Xie F, Sepulveda J, Breitenkamp R, et al. Surface modification of tobacco mosaic virus with "click" chemistry. ChemBioChem 2008;9:519-23. [127] Pilan L. Tailoring the performance of electrochemical biosensors based on carbon nanomaterials via aryldiazonium electrografting. Bioelectrochemistry 2020:107697.

[128] Tufani A, Qureshi A, Niazi JH. Iron oxide nanoparticles based magnetic luminescent quantum dots (MQDs) synthesis and biomedical/biological applications: a review. Mater Sci Eng C 2021;118:111545.

[129] Rohaizad N, Mayorga-Martinez CC, Fojtů M, Latiff NM, Pumera M. Two-dimensional materials in biomedical, biosensing and sensing applications. Chem Soc Rev 2021;50:619-657. [130] Zhao W-W, Xu J-J, Chen H-Y. Photoelectrochemical DNA biosensors. Chem Rev 2014;114:7421-41.

[131] Chen L, Zhang G, Liu L, Li Z. Emerging biosensing technologies for improved diagnostics of COVID-19 and future pandemics. Talanta 2020:121986.

[132] Bu J, Deng Z, Liu H, Li J, Wang D, Yang Y, et al. Current methods and prospects of coronavirus detection. Talanta 2021;225:121977.

[133] Eissa S, Zourob M. Development of a Low-Cost Cotton-Tipped Electrochemical Immunosensor for the Detection of SARS-CoV-2. Anal Chem 2021;93:1826-1833. 
[134] Hillberg A, Brain K, Allender C. Molecular imprinted polymer sensors: implications for therapeutics. Adv Drug Deliv Rev 2005;57:1875-89.

[135] Cheong WJ, Yang SH, Ali F. Molecular imprinted polymers for separation science: a review of reviews. J Sep Sci 2013;36:609-28.

[136] Hoshino Y, Kodama T, Okahata Y, Shea KJ. Peptide imprinted polymer nanoparticles: a plastic antibody. J Am Chem Soc 2008;130:15242-3.

[137] Ahmad R, Félidj N, Boubekeur-Lecaque L, Lau-Truong S, Gam-Derouich S, Decorse P, Lamouri A, Mangeney C. Water-soluble plasmonic nanosensors with synthetic receptors for label-free detection of folic acid. Chem Commun 2015;51:9678-81.

[138] Ahmad R, Griffete Nbw, Lamouri A, Felidj N, Chehimi MM, Mangeney C. Nanocomposites of gold nanoparticles@molecularly imprinted polymers: chemistry, processing, and applications in sensors. Chem Mater 2015;27:5464-78.

[139] Gam-Derouich S, Mahouche-Chergui S, Truong S, Hassen-Chehimi DB, Chehimi MM. Design of molecularly imprinted polymer grafts with embedded gold nanoparticles through the interfacial chemistry of aryl diazonium salts. Polymer 2011;52:4463-70.

[140] Boitard C, Lamouri A, Ménager C, Griffete Nbw. Whole Protein Imprinting over Magnetic Nanoparticles Using Photopolymerization. ACS Appl Polymer Mater 2019;1:928-32.

[141] Rusmini F, Zhong Z, Feijen J. Protein immobilization strategies for protein biochips. Biomacromolecules 2007;8:1775-89.

[142] Farka Z, Mickert MJ, Pastucha M, Mikušová Z, Skládal P, Gorris HH. Advances in Optical Single- Molecule Detection: En Route to Supersensitive Bioaffinity Assays. Angew Chem 2020;59:10746-73.

[143] Kairdolf BA, Qian X, Nie S. Bioconjugated nanoparticles for biosensing, in vivo imaging, and medical diagnostics. Anal Chem 2017;89:1015-31.

[144] Qi M, Zhang Y, Cao C, Zhang M, Liu S, Liu G. Decoration of reduced graphene oxide nanosheets with aryldiazonium salts and gold nanoparticles toward a label-free amperometric immunosensor for detecting cytokine tumor necrosis factor- $\alpha$ in live cells. Anal Chem 2016;88:9614-21.

[145] Alarfaj NA, El-Tohamy MF. A label-free electrochemical immunosensor based on gold nanoparticles and graphene oxide for the detection of tumor marker calcitonin. New J Chem 2017;41:11029-35.

[146] Serafín V, Torrente-Rodríguez R, González-Cortés A, De Frutos PG, Sabaté M, Campuzano S, et al. An electrochemical immunosensor for brain natriuretic peptide prepared with screen-printed carbon electrodes nanostructured with gold nanoparticles grafted through aryl diazonium salt chemistry. Talanta 2018;179:131-8.

[147] Domenici F, Bizzarri AR, Cannistraro S. Surface-enhanced Raman scattering detection of wild-type and mutant p53 proteins at very low concentration in human serum. Anal Biochem 2012;421:9-15.

[148] Rawson F, Yeung C, Jackson S, Mendes P. Tailoring 3D single-walled carbon nanotubes anchored to indium tin oxide for natural cellular uptake and intracellular sensing. Nano Lett 2013;13:1-8.

[149] Hou J-T, Ren WX, Li K, Seo J, Sharma A, Yu X-Q, et al. Fluorescent bioimaging of pH: from design to applications. Chem Soc Rev 2017;46:2076-90. 
[150] Zhang J, Yu S-H. Carbon dots: large-scale synthesis, sensing and bioimaging. Mater Today 2016;19:382-93.

[151] Luo Y, Xiao Y, Onidas D, Iannazzo L, Ethève-Quelquejeu M, Lamouri A, et al. Raman reporters derived from aryl diazonium salts for SERS encoded-nanoparticles. Chem Commun 2020;56:6822-6825.

[152] Frasconi M, Marotta R, Markey L, Flavin K, Spampinato V, Ceccone G, et al. Multi- functionalized carbon nano- onions as imaging probes for cancer cells. Chem Eur J 2015;21:19071-80.

[153] Zhao Y, Tong L, Li Z, Yang N, Fu H, Wu L, et al. Stable and multifunctional dye-modified black phosphorus nanosheets for near-infrared imaging-guided photothermal therapy. Chem Mater 2017;29:7131-9.

[154] Paiva I, Mattingly S, Wuest M, Leier S, Vakili MR, Weinfeld M, et al. Synthesis and analysis of ${ }^{64} \mathrm{Cu}$-labeled GE11-modified polymeric micellar nanoparticles for EGFR-targeted molecular imaging in a colorectal cancer model. Mol Pharm 2020;17:1470-81.

[155] Hajipour MJ, Fromm KM, Ashkarran AA, de Aberasturi DJ, de Larramendi IR, Rojo T, et al. Antibacterial properties of nanoparticles. Trends Biotechnol 2012;30:499-511.

[156] Cloutier M, Mantovani D, Rosei F. Antibacterial coatings: challenges, perspectives, and opportunities. Trends Biotechnol 2015;33:637-52.

[157] Kawai K, Narushima T, Kaneko K, Kawakami H, Matsumoto M, Hyono A, et al. Synthesis and antibacterial properties of water-dispersible silver nanoparticles stabilized by metal-carbon $\sigma$-bonds. Appl Surf Sci 2012;262:76-80.

[158] Amiri A, Zardini HZ, Shanbedi M, Maghrebi M, Baniadam M, Tolueinia B. Efficient method for functionalization of carbon nanotubes by lysine and improved antimicrobial activity and water-dispersion. Mater Lett 2012;72:153-6.

[159] Metwally NH, Saad GR, Abd El-Wahab EA. Grafting of multiwalled carbon nanotubes with pyrazole derivatives: characterization, antimicrobial activity and molecular docking study. Int J Nanomed 2019;14:6645.

[160] Some S, Ho S-M, Dua P, Hwang E, Shin YH, Yoo H, et al. Dual functions of highly potent graphene derivative-poly-l-lysine composites to inhibit bacteria and support human cells. Acs Nano 2012;6:7151-61.

[161] Huang J, Yin Z, Wu J. Covalent attachment of chitosan to graphene via click chemistry for superior antibacterial activity. Mater Adv 2020;1:579-83.

[162] Farjadian F, Ghasemi A, Gohari O, Roointan A, Karimi M, Hamblin MR. Nanopharmaceuticals and nanomedicines currently on the market: challenges and opportunities. Nanomedicine 2019;14:93-126.

[163] Barosi A, Berisha A, Mangeney C, Pinson J, Dhimane H, Dalko PI. Efficient construction of a redox responsive thin polymer layer on glassy carbon and gold surfaces for voltage-gated delivery applications. Mater Adv 2021;2:2358-2365. 


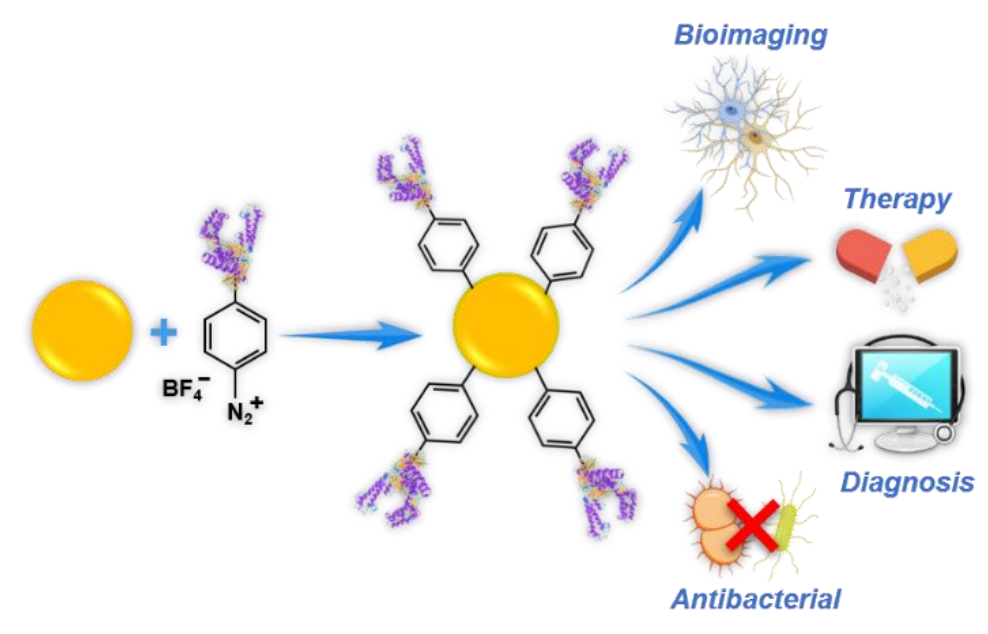

\section{Highlights}

- Diazonium salts extend the toolbox of NPs surface chemistry for biomedicine

- Protocols for NPs functionalization with diazonium salts are fast and user-friendly

- Aryldiazonium salt chemistry results in robust interfacial NPs-C covalent bonds

- Diazonium salts were used for drug delivery, biosensors, imaging and antibacterial NPs

- Diazonium salts allow the grafting of a large choice of (bio-)molecules on NPs 